NBER WORKING PAPER SERIES

\title{
THE CARRY TRADE AND FUNDAMENTALS: NOTHING TO FEAR BUT FEER ITSELF
}

\author{
Òscar Jordà \\ Alan M. Taylor \\ Working Paper 15518 \\ http://www.nber.org/papers/w15518
NATIONAL BUREAU OF ECONOMIC RESEARCH
1050 Massachusetts Avenue
Cambridge, MA 02138
November 2009

\begin{abstract}
Taylor has been supported by the Center for the Evolution of the Global Economy at UC Davis and Jorda by DGCYT Grant (SEJ2007-63098-econ); part of this work was completed whilst Taylor was a Houblon-Norman/George Fellow at the Bank of England; all of this research support is gratefully acknowledged. We thank Travis Berge and Yanping Chong for excellent research assistance. We acknowledge helpful comments from Vineer Bhansali, Richard Meese, Michael Melvin, Stefan Nagel, Michael Sager, Mark Taylor, and seminar participants at The Bank of England, Barclays Global Investors, London Business School, London School of Economics, the 3rd annual JIMF-SCCIE conference, the NBER IFM program meeting, and PIMCO. All errors are ours. The views expressed herein are those of the author(s) and do not necessarily reflect the views of the National Bureau of Economic Research.
\end{abstract}

NBER working papers are circulated for discussion and comment purposes. They have not been peerreviewed or been subject to the review by the NBER Board of Directors that accompanies official NBER publications.

(C) 2009 by Òscar Jordà and Alan M. Taylor. All rights reserved. Short sections of text, not to exceed two paragraphs, may be quoted without explicit permission provided that full credit, including $\odot$ notice, is given to the source. 
The Carry Trade and Fundamentals: Nothing to Fear But FEER Itself

Òscar Jordà and Alan M. Taylor

NBER Working Paper No. 15518

November 2009, Revised November 2009

JEL No. C44,F31,F37,G14,G15,G17

\begin{abstract}
$\underline{\text { ABSTRACT }}$
The carry trade is the investment strategy of going long in high-yield target currencies and short in low-yield funding currencies. Recently, this naive trade has seen very high returns for long periods, followed by large crash losses after large depreciations of the target currencies. Based on low Sharpe ratios and negative skew, these trades could appear unattractive, even when diversified across many currencies. But more sophisticated conditional trading strategies exhibit more favorable payoffs. We apply novel (within economics) binary-outcome classification tests to show that our directional trading forecasts are informative, and out-of-sample loss-function analysis to examine trading performance. The critical conditioning variable, we argue, is the fundamental equilibrium exchange rate (FEER). Expected returns are lower, all else equal, when the target currency is overvalued. Like traders, researchers should incorporate this information when evaluating trading strategies. When we do so, some questions are resolved: negative skewness is purged, and market volatility (VIX) is uncorrelated with returns; other puzzles remain: the more sophisticated strategy has a very high Sharpe ratio, suggesting market inefficiency.
\end{abstract}

Òscar Jordà

Dept. of Economics

UC, Davis

One Shields Ave.

Davis, CA 95616

ojorda@ucdavis.edu

Alan M. Taylor

Department of Economics

University of California, Davis

One Shields Avenue

Davis, CA 95616

and NBER

amtaylor@ucdavis.edu 
Once a relatively obscure corner of international finance, the naïve carry trade (borrowing in low interest rate currencies and investing in high interest rate currencies, despite the exchange rate risk) has drawn increasing attention in recent years, within and beyond academe, and especially as the volume of carry trade activity multiplied astronomically.

Inevitably, press attention has often focused on the personal angle and episodes of financial implosion. In 2007, The New York Times reported on the disastrous losses suffered by the "FX Beauties" club and other Japanese retail investors during an episode of yen appreciation; one highly-leveraged housewife lost her family's entire life savings within a week. ${ }^{1}$ By the fall of 2008 attention was grabbed by an even more brutal squeeze on carry traders from bigger yen movese.g., up 60\% against the AUD over 2 months, and up 30\% against GBP (including 10\% moves against both in five hours on the morning of October 24). Money managers on the wrong side saw their funds blowing up, supporting the June 2007 prediction of Jim O'Neill, chief global economist at Goldman Sachs, who had said of the carry trade that "there are going to be dead bodies around when this is over." ${ }^{2}$

But for the dismal science, a market crash can be celebrated as an ill wind. Persistent carry trade profits in the 2002-2007 period appeared to strike at the core of the efficient market hypothesis (EMH) until the financial collapse of 2008 restored a modicum of credibility by exploding many seemingly profitable strategies. ${ }^{3}$ Still, we think caution is needed in the interpretation of the recent carry trade era. Our paper uncovers more sophisticated carry trade strategies that would have escaped the debacle of 2008 largely unscathed, once more reigniting the debate about whether such profit opportunities can be reconciled with standard models of risk adjustment.

Our paper is not the only recent contribution to a new carry trade literature, and joins a resurgent debate on the carry trade which revisits many old questions: Are there returns to currency speculation? Are the returns predictable? Is there a failure of market efficiency? We are still far from a consensus, but the present state of the literature, how it got there, and how it relates to the interpretations of the current market turmoil, can be summarized in a just few moments, so to speak. ${ }^{4}$

The first point concerns the first moment of returns. There have been on average positive returns to naïve carry trade strategies for long periods. ${ }^{5}$ Put another way, the standard finding

\footnotetext{
${ }^{1}$ Martin Fackler, "Japanese Housewives Sweat in Secret as Markets Reel," New York Times, September 16, 2007.

2 Ambrose Evans Pritchard. "Goldman Sachs Warns of 'Dead Bodies' after Market Turmoil," Daily Telegraph, June 3, 2007.

3 See, for example, Richard Thaler in "Efficiency and beyond," The Economist, July 16th, 2009.

${ }^{4}$ For a full survey of foreign exchange market efficiency see Chapter 2 in Sarno and Taylor (2002), on which we draw here.

${ }^{5}$ We prefer to focus on the period of unfettered arbitrage in the current era financial globalization-that is, from the mid 1980s on, for major currencies. Staring in the 1960s the growth of the Eurodollar markets had permitted offshore currency arbitrage to develop. Given the increasingly porous nature of the Bretton Woods era capital controls, and the tidal wave of financial flow building up, the dams started to leak, setting the stage for the trilemma to bite in the crisis of the Bretton Woods regime in 1970-73. Floating would permit capital account liberalization, but the process was fitful, and not until 1990s was the transition complete in Europe (Bakker and Chapple 2002). Empirical evidence suggests significant barriers of 100bps or more even to riskless arbitrage in the 1970s and even into the early 1980s (Frenkel and Levich 1975; Clinton 1988; Obstfeld and Taylor 2004). Taking these frictions as evidence of imperfect capital mobility we prefer to exclude the 1970s and the early 1980s from our empirical work. Other work, e.g. Burnside, Eichenbaum, Kleshchelski, and Rebelo (2008a,b) includes data back to the the 1970s.
} 
of a "forward discount bias" in the short run means that exchange rate losses will not fully offset the interest differential gains of the naïve carry strategy. ${ }^{6}$ This finding is often misinterpreted as a failure of uncovered interest parity; but UIP is an ex-ante, not an ex-post, condition - and the evidence, albeit limited, shows that average ex-ante exchange rate expectations (e.g., from surveys of traders) are not so far out of line with interest differentials. ${ }^{7}$ Rather, expectations themselves seem to be systematically wrong. In this view, ex-post profits appeared to be both predictable and profitable, contradicting the risk-neutral efficient markets hypothesis. Indeed, our paper builds on this tradition using both regression and trading-algorithm approaches. ${ }^{8}$ However, over periods of a decade or two it is quite difficult to reject ex-post UIP, suggesting that interest arbitrage holds in the long run, and that the possible profit opportunities are a matter of timing. ${ }^{9}$

The second point concerns the second moment of returns. If positive ex-ante returns are not arbitraged away, one way to rationalize them might be that they are simply too risky (volatile) to attract additional investors who might bid them away. This explanation has much in common with other finance puzzles, like the equity premium puzzle. The annual reward-to-variability ratio or Sharpe ratio of the S\&P 500, roughly 0.4, can be taken as a benchmark level of risk adjusted return. But anecdotal evidence (see Lyons, 2001) suggests that many relevant marginal investors (e.g., proprietary trading desks) have little interest in strategies with annual Sharpe ratios below 1 , and it would be natural for this hurdle to apply to a currency strategy as well. Historical data show that for all individual currency pairs, this hurdle has not been met using naïve carry trade strategies. Obviously, diversification in a portfolio across many currency pairs can improve performance, since returns on different currencies are not perfectly correlated. But even then, the data show that the hurdle of 1 is hard to beat in the long run for the G10 universe of currencies. Thus, the seemingly excess returns to the naïve carry strategy may be explicable, at least in part, as compensation for volatility. ${ }^{10}$

Finally, we turn to the third point of near consensus, on the third moment of returns. Naïve carry trade returns are negatively skewed. The lower-tail risk means that trades are subject to a risk of pronounced periodic crashes - what is often referred to as a peso problem. Such a

\footnotetext{
6 Seminal studies of the forward discount puzzle include Frankel (1980), Bilson (1981), Fama (1984), Froot and Thaler (1990), and Bekaert and Hodrick (1993).

7 Seminal works on survey expectations include Dominguez (1986) and Froot and Frankel (1987, 1989). For an update see Chinn and Frankel (2002).

8 A standard test of the predictability of returns (the "semi-strong" form of market efficiency) is to regress returns on an ex ante information set. The seminal work is Hansen and Hodrick (1980). Other researchers deploy simple profitable trading rules as evidence of market inefficiency (Dooley and Shafer 1984; Levich and Thomas 1993; Engel and Hamilton 1990).

9 Support for long-run UIP was found using long bonds by Fujii and Chinn (2000) and Alexius (2001), and using short rates by Sinclair (2005).

${ }^{10}$ It is an open question whether expanding the currency set to include minor currencies, exotics, and emerging markets can add further diversification and so enhance the Sharpe ratio, or whether these benefits will be offset by illiquidity, trading costs, and high correlations/skew. Burnside, Eichenbaum, Kleshchelski and Rebelo (2006) compute first, second, and third moments for individual currencies and portfolio-based strategies for major currencies and some minor currencies. In major currencies the transaction costs associated with bid-ask spreads are usually small, although $5-10$ bps per trade can add up if an entire portfolio is churned every month (i.e., $60-120$ bps annual). Burnside, Eichenbaum, and Rebelo (2007) explore emerging markets with adjustments for transaction costs. Both studies conclude that there are profit opportunities net of such costs, but the Sharpe ratios are low. Moreover, Sager and Taylor (2008) argue that the Burnside et al. returns and Sharpe ratios may be overstated. Pursuing a different strategy, however, using information in the term structure, Sager and Taylor are able to attain Sharpe ratios of 0.88 for a diversified basket of currencies in back testing.
} 
description applies to the aforementioned disaster events suffered by yen carry traders in 2007 and 2008 (and their predecessors in 1998). However, many competing investments, like the S\&P500, are also negatively skewed, so the question is once more relative. And once again echoing the central limit theorem, this time for higher moments, while individual currency pairs may exhibit high skew, we know that diversification across currency pairs can be expected to drive down skewness in a portfolio. But for naïve strategies some negative skew still remains under diversification, and it is then unclear whether excess returns are a puzzle, or required compensation for skew (and/or volatility). ${ }^{11}$

In light of the risk/return features of the carry trade, it seems desirable to articulate a formal test of the EMH with currency data. However, a test of EMH is always a joint test involving the correct model of risk adjustment and the correct statistical analysis of the data. Unfortunately, there is still no consensus about what the true model of risk adjustment is. ${ }^{12}$ Thus, any characterization of a risk/returns anomaly would be subject to the unverifiable criticism that investor preferences were inadequately modeled. For this reason, our paper focuses on the statistical analysis part of the joint test, and finds that - however low a statistical hurdle might be - the sophisticated carry trade strategies that we discuss appear to exhibit attractively high returns and low risk, even throughout the turbulent period of the last half of 2008. A summary of the contributions of our paper is as follows:

- We start from common ground and confirm the above findings for our data; naïve carry trades are profitable but, even when diversified, they have low Sharpe ratios and negative skew. ${ }^{13}$

- We show that an important explanatory variable has been omitted from influential recent studies; the deviation from the fundamental equilibrium exchange rate (FEER) is an important predictor of exchange rates. ${ }^{14}$

- Moreover, carry returns may be better explained in a nonlinear model, and our preferred nonlinear model draws together extant ideas from the UIP and PPP literature. The nonlinear model's regimes weigh two signals, a "greed" factor (potential carry trade interest gains plus momentum) and a "fear" factor (potential mean reversion to FEER).

\footnotetext{
${ }^{11}$ Brunnermeier, Nagel and Pedersen (2008) focus on the "rare event" of crash risk as an explanation for carry trade profits. Burnside, Eichenbaum, Kleshchelski, and Rebelo (2008a) argue that peso problems cannot explain carry trade profits, although in a different version of the same paper (2008b), they argue to the contrary.

12 An example of this lack of consensus is the more recent and contentious use of consumption-based asset pricing models in the carry trade context. Lustig and Verdelhan (2007) claimed that the relatively low naïve carry trade returns may be explicable in a consumption-based model with reasonable parameters. Burnside (2007) challenged the usefulness of this approach. Returns to our systematic trading rules have very different moments, however, with mean returns twice as large as the typical naïve strategy, leaving a considerable premium to be explained in either framework. See also Burnside, Eichenbaum, Kleshchelski, and Rebelo (2006) who find no correlation between their carry trade returns and a wide range of typical "risk factors" used in finance.

13 Note that throughout this article we implicitly assume that the end investor dislikes negative skew, all else equal. Of course, due to well known principal-agent problems arising from asymmetric compensation structures, asset managers may be quite happy to embrace large negative skew if they can obtain larger returns and associated performance fees in the short run before their fund blows up.

${ }^{14}$ Bilson (1984) is an early example where PPP was proposed as a forecasting model.
} 
- Inclusion of the FEER control variable improves not only the statistical performance of the model, it also enhances the financial performance of trading rules based on the model, and much more so than diversification alone. For simplicity and comparability we apply the model to equal-weight portfolio strategies among G10 currencies, a standard backtesting laboratory. Trading on a long-short directional signal for each currency we achieve Sharpe ratios well in excess of 1 over long periods, and attain zero or even positive skew.

- To support the claim that our directional forecasts beat a coin toss or rival strategies like naïve carry, we do out-of-sample testing using innovative loss functions (Giacomini and White 2006). We also employ (as far as we know, for the first time in economics) a set of powerful tools that have been widely used in other fields, such as medical statistics: the receiver operating characteristic curve, or ROC curve, and its associated hypothesis tests. For applications in finance we apply an extension of the ROC curve, called ROC* (Jordà and Taylor 2009), which allows for directional predictions to be weighted by returns, in the spirit of gain-loss performance measures (Bernardo and Ledoit 2000).

- We also compare our approach to rival crash protection strategies. One suggestion is that carry trade skew is driven by market stress and liquidity events (Brunnermeier et al. 2008); but we find that VIX signals provide no additional explanatory or predictive power in our preferred forecasting framework. Another approach suggests that options provide a way to hedge downside risk (Burnside, Eichenbaum, Kleshchelski, and Rebelo, 2008ab); but these strategies are very costly to implement compared to our trading rule.

- Finally we perform out-of-sample tests and explore real-world trading strategies for the years up to and including the 2008 financial crisis, looking at our model performance and actual exchange traded funds. The naïve models and crude ETFs crashed horribly in 2008, wiping out years of gains. More sophisticated ETFs resembling our preferred model weathered the storm remarkably well with barely any drawdown.

To conclude, we find that in the past, whilst naïve carry strategies may not have offered adequate compensation for risk (volatility and skew), more sophisticated strategies that accounted for long-run real exchange rate fundamentals could have easily surmounted that hurdle. This provides support for currency strategies that augment carry and momentum signals with a value signal based on real fundamentals. Many sophisticated funds with limited access have pursued such strategies in the past, but the recent arrival of simple, passive ETFs with these same features raises the issue of how much "true alpha" active currency managers create. It also begs the question how long any such excess returns might persist before being arbitraged away. ${ }^{15}$

In addition to extending a growing literature on the nature of carry trade dynamics, our paper also provides a touchstone for ongoing theoretical work that attempts to characterize the form and extent of deviations from the efficient markets hypothesis. Our work is sympathetic to a

\footnotetext{
${ }^{15}$ Pojarliev and Levich $(2007,2008)$ argue that active managers deliver less alpha than claimed, and that much of their returns can be described as quasi-beta with respect to style factors like carry, momentum, and value that are now captured in passive indices and funds.
} 
well-established view that asset prices can deviate from their fundamental value for some time, before a "snap back" occurs (Poterba and Summers 1986; Plantin and Shin 2007). Recent theory has focused on what might permit the deviation, and what then triggers the snap. In FX markets, work in this vein includes models of noise traders, heterogeneous beliefs, rational inattention, liquidity constraints, financial stress, herding, "behavioral" effects, and other factors that may serve to limit arbitrage (e.g., Shleifer and Vishny 1997; Jeanne and Rose 2002; Baccheta and van Wincoop 2006; Fisher 2006; Brunnermeier et al. 2008; Ilut 2008; Melvin and M. P. Taylor 2009).

\section{Statistical Design}

Our primary objectives are to investigate the dynamic links between the excess returns to carry trade and deviations from FEER; to generate forecasts with which to construct out-of-sample formal predictive evaluation; and hence to construct carry trade strategies whose out-of-sample returns can be evaluated for profitability and risk.

The data for the analysis consists of a panel of nine countries (Australia, Canada, Germany, Japan, Norway, New Zealand, Sweden, Switzerland, and the United Kingdom) set against the U.S. over the period January 1986 to December, 2008, observed at a monthly frequency (i.e., the "G10" sample). ${ }^{16}$ The variables in this data-set include the end-of-month nominal exchange rate expressed in U.S. dollars per foreign currency units and whose logarithm we denote as $e_{t}$; the one-month London interbank offered rates (LIBOR) denoted as $i_{t}$ for the U.S. and $i_{t}^{*}$ for any of the nine counterparty countries; and the consumer price index, whose logarithm is denoted as $p_{t}$ for the U.S. and $p_{t}^{*}$ otherwise. Data on exchange rates and the consumer price index are obtained from the IFS database whereas data on LIBOR are obtained from the British Banker's Association (www.bba.org.uk) and Global Financial Data (globalfinacialdata.com).

The primary variable of interest to us can be thought of as momentum, denoted $m_{t}$. Momentum refers to the ex-post nominal excess returns of a carry trade, specifically approximated by

$$
m_{t+1}=\Delta e_{t+1}+\left(i_{t}^{*}-i_{t}\right)
$$

In the absence of barriers or limits to arbitrage, and assuming that the efficient markets hypothesis (EMH) holds, the ex-ante value of momentum for the next month should be zero at any time $t$, that is $E_{t} m_{t+1}=E_{t} \Delta e_{t+1}+\left(i_{t}^{*}-i_{t}\right)=0$.

Momentum can also be expressed in terms of real excess returns as

$$
m_{t+1}=\Delta q_{t+1}+\left(r_{t}^{*}-r_{t}\right)
$$

where $r_{t}=i_{t}-\pi_{t+1}$ with $\pi_{t+1}=\Delta p_{t+1}$, and similarly for $r_{t}^{*}$ and $\pi_{t+1}^{*}$; and is $q_{t+1}=\bar{q}+e_{t+1}+$ $\left(p_{t+1}^{*}-p_{t+1}\right)$, where $q$ denotes the log real exchange rate. Thus, $\Delta q_{t+1}=\Delta e_{t+1}+\left(\pi_{t+1}^{*}-\pi_{t+1}\right)$ and the equivalence between (1) and (2) is readily apparent. Under the assumption of (weak) purchasing power parity, $\bar{q}$ is the mean FEER to which $q_{t}$ reverts, so $q_{t}-\bar{q}$ is a stationary variable

\footnotetext{
${ }^{16}$ Data for the Germany after 1999 are constructed with the EUR/USD exchange rate and the fixed conversion rate of $1.95583 \mathrm{DEM} / \mathrm{EUR}$.
} 
and hence a valid cointegrating term. In a more general setting, and in the out-of-sample analysis below, $\bar{q}$ may be time varying, when there is drift in the FEER due to productivity effects or other factors.

The dynamic interactions between nominal exchange rates, inflation and nominal interest rate deviations are the constituent elements of a system whose linear combinations explain the dynamic behavior of momentum and FEER conveniently. ${ }^{17}$ Specifically, we consider the system

$$
\Delta \mathbf{y}_{t+1}=\left[\begin{array}{c}
\Delta e_{t+1} \\
\pi_{t+1}^{*}-\pi_{t+1} \\
i_{t}^{*}-i_{t}
\end{array}\right] .
$$

Under the assumption of purchasing power parity, $e_{t+1}$ and $\left(p_{t+1}^{*}-p_{t+1}\right)$ may be $I(1)$ variables, but they are cointegrated; therefore, a natural representation of the dynamics of $\Delta \mathbf{y}_{t+1}$ in (3) is with a vector error correction model (VECM). Although including $\left(i_{t}^{*}-i_{t}\right)$ in expression (3) may appear peculiar because it is information known at time $t+1$, expression (3) focuses on forecasting $m_{t+1}$ with the specification for the first equation in the VECM for $\Delta \mathbf{y}_{t+1}$.

\section{A Trading Laboratory for the Carry Trade}

This section investigates the econometric properties of the returns to the carry trade and for this reason, it is legitimate to use the full sample of available data. Once we establish the elementary features of the problem, the next section proceeds with the "gold standard" of formal out-of-sample predictive ability evaluation for the set of competing carry trade strategies.

\subsection{Statistical Properties of Exchange Rates and FEER}

Our forecasting model hinges on the error correction representation of the equation for $\Delta e_{t}$ in the system of expression (3), where we take $q_{t+1}=\bar{q}+e_{t+1}+\left(p_{t+1}^{*}-p_{t+1}\right)$ to be a cointegrating term. ${ }^{18}$ A natural impulse is to determine the stationarity properties of the constituent elements of expression (3) so as to verify that $q_{t+1}$ is a proper cointegrating term. Such steps are natural when the objective of the analysis is to directly examine whether purchasing power parity holds in the data; when one is interested in determining the speed of adjustment to long-run equilibrium; and hence to ensure that the estimators and inference are constructed with the appropriate nonstandard asymptotic machinery. However interesting it is to investigate these issues, they are of second order importance for our analysis given our stated focus on predictive ability and derivation of profitable investment strategies - the Beveridge-Nelson representation of the first equation in expression (3) is valid regardless of whether there is cointegration. For this reason, we provide a far less extensive analysis of these issues for our panel data than is customary and refer the reader to the extensive literature on panel PPP testing (e.g., see Taylor and Taylor 2004).

\footnotetext{
${ }^{17}$ It would be straightforward to augment this model with an order-flow element, as in the VAR system of Froot and Ramadorai (2005).

18 Note that in all estimations in this paper, $\bar{q}$ is absorbed in country specific intercept terms, so we are testing relative PPP not absolute PPP.
} 
Table 1: Panel Cointegration Tests

\begin{tabular}{|c|c|c|c|c|c|c|c|c|}
\hline \multirow[b]{3}{*}{ Test } & \multicolumn{4}{|c|}{ 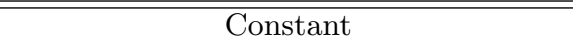 } & \multicolumn{4}{|c|}{ "Constant + Trend } \\
\hline & \multicolumn{2}{|c|}{ Raw } & \multicolumn{2}{|c|}{ Demeaned } & \multicolumn{2}{|c|}{ Raw } & \multicolumn{2}{|c|}{ Demeaned } \\
\hline & stats & $p$ & stats & $p$ & stats & $p$ & stats & $p$ \\
\hline \multicolumn{9}{|l|}{$\overline{\text { Panel }}$} \\
\hline$v$ & $2.50^{* *}$ & 0.017 & $3.82^{* *}$ & 0.000 & 0.14 & 0.395 & $2.04^{*}$ & 0.050 \\
\hline$\rho$ & $-1.68^{*}$ & 0.097 & $-2.22^{* *}$ & 0.034 & -0.56 & 0.340 & $-1.78^{*}$ & 0.079 \\
\hline $\mathrm{PP}$ & -1.59 & 0.113 & $1.68^{*}$ & 0.097 & -1.09 & 0.220 & $-1.71^{*}$ & 0.093 \\
\hline $\mathrm{ADF}$ & 0.99 & 0.245 & -0.54 & 0.345 & 1.27 & 0.179 & -0.39 & 0.370 \\
\hline \multicolumn{9}{|c|}{ Group } \\
\hline$\rho$ & -0.51 & 0.350 & $-1.71^{*}$ & 0.092 & 0.48 & 0.356 & $-2.12^{* *}$ & 0.042 \\
\hline $\mathrm{PP}$ & -0.98 & 0.246 & -1.65 & 0.103 & -0.40 & 0.368 & $-2.06^{* *}$ & 0.048 \\
\hline $\mathrm{ADF}$ & $7.31^{* *}$ & 0.000 & 0.59 & 0.335 & $7.16^{* *}$ & 0.0009 & 0.74 & 0.303 \\
\hline
\end{tabular}

Notes: We use the same definitions of each test as in Pedroni (1999). The tests are residual-based. We consider tests with constant term and no trend, and with constant and time trend. The first 4 rows describe tests that pool along the within-dimension whereas the last 3 rows describe tests that pool along the between-dimension. The tests allow for heterogeneity in the cointegrating vectors, the dynamics of the error process and across cross-sectional units. ${ }^{* *}$ indicates rejection of the null of no-cointegration at the $5 \%$ level, or * $10 \%$ level. The sample is January 1986 to December 2008.

Instead, we investigate the properties of $q_{t+1}$ directly with a battery of cointegration tests that pool the data to improve the power of the tests (while accounting for different forms of heterogeneity in cross-section units) and based on Pedroni $(1999,2004)$. The results of these tests are summarized in Table 1, with the particulars of each test explained therein. Broadly speaking, while not overwhelming, it seems reasonable to conclude that the data support our thinking of $q_{t+1}$ as a valid cointegrating error-correction term.

While the results of Table 1 are informative regarding the relative strength of PPP, we will show momentarily that there is valuable predictive information contained in real exchange rate fundamentals for use in one period-ahead forecasts, which might form the basis of a trading strategy. Hence, we try various forecasting models, from naïve models (e.g., simple carry trades) to more sophisticated models (e.g., nonlinear models of UIP and PPP dynamics). The models are then evaluated in two ways: first from a statistical standpoint, by looking at the in-sample fit and out-of-sample predictive power; and second from a trading standpoint, by examining how implementing these strategies would have affected a currency manager's returns, volatility, Sharpe ratios, and skewness for the sample period.

\subsection{Two Naïve Models}

Table 2 presents the one-month ahead forecasts of the change in the log nominal exchange rate based on two naïve models. Model 1, denoted "Naïve," imposes the assumption that the exchange rate follows a random walk. All regressors are omitted so there is, in fact, no estimated model. This is simply the benchmark or null model. However crude it may be, this is still a model that one might use as a basis for a hypothetical trading strategy. ${ }^{19}$ The trading strategy is long high

\footnotetext{
19 In the real world, investors would not trade only at a monthly frequency; they would be concerned about drawdowns, and would probably augment any strategy with stop-loss behavior. We abstract from these issues.
} 
Table 2: Two Naïve Models

\begin{tabular}{|c|c|c|}
\hline$\overline{\text { Model }}$ & $\begin{array}{c}(1) \\
\text { Naïve }\end{array}$ & $\begin{array}{c}(2) \\
\text { Naïve ECM }\end{array}$ \\
\hline \multicolumn{3}{|l|}{ (a) Model parameters } \\
\hline Dependent variable & $\Delta e_{j t}$ & $\Delta e_{j t}$ \\
\hline$q_{j t}-\bar{q}_{j}$ & - & $\begin{array}{c}-0.0235^{* *} \\
(0.0047)\end{array}$ \\
\hline$R^{2}$, within & - & .0119 \\
\hline$F$ & - & $\mathrm{F}(1,2447)=25.39$ \\
\hline Fixed effects & 一 & Yes \\
\hline Periods & 276 & 276 \\
\hline Currencies (relative to US\$) & 9 & 9 \\
\hline Observations & 2484 & 2484 \\
\hline \multicolumn{3}{|l|}{ (b) Trading performance $\dagger$} \\
\hline \multicolumn{3}{|l|}{ Predicted profits } \\
\hline Mean & 0.0022 & 0.0029 \\
\hline Std. dev. & 0.0018 & 0.0025 \\
\hline Skewness & 2.2348 & 1.5876 \\
\hline C.v. & 0.8247 & 0.8766 \\
\hline \multicolumn{3}{|l|}{ Forecast errors } \\
\hline Mean & 0.0005 & 0.0004 \\
\hline Std. dev. & 0.0299 & 0.0296 \\
\hline Skewness & -0.7278 & -0.3705 \\
\hline C.v. & 62.1150 & 71.6838 \\
\hline \multicolumn{3}{|l|}{ Actual profits } \\
\hline Mean & 0.0026 & 0.0033 \\
\hline Std. dev. & 0.0299 & 0.0298 \\
\hline Skewness & -0.6743 & -0.0043 \\
\hline C.v. & 11.3310 & 8.9930 \\
\hline
\end{tabular}

$\uparrow$ Statistics for trading profits are net, monthly, pooled.

Note: C.v. = coefficient of variation $=$ ratio of standard deviation to mean. Standard errors in parentheses; ** $(*)$ denotes significant at the $95 \%$ (90\%) confidence level. Estimation is by ordinary least squares. In column (1), there is no model estimation as coefficients are assumed to be zero and $e$ follows a random walk.

yield, short low yield (i.e., based on the sign of the signal which is the interest differential) - so panels (b)-(d) explore the performance characteristics of the pooled set of trades based on such a strategy, for all 9 currencies against the U.S. dollar and all 276 months (2484 observations). In pooled data here, and below, the index $j$ denotes the non-U.S. currency, and $t$ the month.

The findings are as expected. Average predicted profits for all trades (all currencies, all months) are about 20 basis points (bps) per month, positively skewed, but with a similar standard deviation. Monthly forecast errors are a serious problem, with a large standard deviation of $300 \mathrm{bps}$, and a large negative skew of -0.73 due to "rare event" crashes. As a result actual trading profits are 26 bps per month, with a standard deviation of 300 bps-implying a truly awful monthly Sharpe ratio of less than 0.1. The pooled trades also have a serious negative skew of -0.67 .

Model 2, denoted "Naïve ECM," augments the Naïve model: we embrace the idea that real exchange rate fundamentals may have predictive power, in that currencies overvalued (undervalued) relative to FEER might be expected to face depreciation (appreciation) pressure. Now in panel (a) the one-month-ahead forecast equation has just a single, lone time-varying regressor, 
the lagged real exchange rate deviation, plus currency-specific fixed effects which are not shown. The coefficient on the real exchange rate term of -0.02 is statistically significant and indicates that reversion to FEER occurs at a convergence speed of about $2 \%$ per month, which implies that deviations have a half-life of 36 months - well within the consensus range of the PPP literature.

In panel (b) the potential virtues of a FEER based trading approach start to emerge, but only weakly. From a trader's perspective, the results are little better with Model 2: forecast profits are higher and more positively skewed. But we also see the flipside: forecast errors are smaller and the negative skew of the error is reduced, although it is still an irksome -0.37 . Thus, although pooled actual ex-post returns in Model 2 have the same mean and volatility (and hence the same feeble Sharpe ratio) as in Model 1, their skewness has been cut from -0.73 to -0.37 : a gain, if only a modest one.

By focusing mainly on unconditional naïve carry trade returns, some influential academic papers have concluded that crash risk and peso problems are important features of the FX market. Table 2 may be extremely naïve, but it suffices to launch the start of a counterargument. It shows that an allowance for real exchange rate fundamentals can limit adverse skewness from the carry trade, and it is indeed well known that successful strategies do just that, as we shall see in a moment. However, we do not stop here, since we have the tools to explore superior model specifications that deliver trading strategies with even higher ex post actual returns, lower volatilities, and negligible (or positive) skew.

\subsection{Two Linear Models}

Table 3 displays the one-month-ahead forecasts from the richer flexible-form exchange rate models discussed in the previous section. Model 3 is based on a regression of the change in the nominal exchange rate on the first lag of the change in the nominal exchange rate, inflation, and the interest rate differentials (this model is labeled VAR since it would correspond to the first equation of a vector autoregressive model for $\Delta \mathbf{y}_{t+1}$ in expression 3). Model 4 extends the specification of Model (3) with the real exchange term and is therefore labeled VECM, by analogy with vector error-correction.

As with the Naïve ECM (Model 2) a plausible convergence speed close to $3 \%$ per month is estimated. Other coefficients conform to standard results and folk wisdom. The positive coefficient on the lagged change in the nominal exchange rate of 0.12 suggests a modest but statistically significant momentum effect. The positive coefficient on the lagged interest differential, closer to +1 than -1 , conforms to the well known forward discount puzzle: currencies with high interest rates tend to appreciate all else equal. The positive coefficient on the inflation differential conforms to recent research findings that "bad news about inflation is good news for the exchange rate" (Clarida and Waldman 2007): under Taylor rules, high inflation might be expected to lead to monetary tightening and future appreciation.

We can see that these models offer some improvement as compared to the Naïve ECM (Model 2 ). The $R^{2}$ is higher and the explanatory variables are statistically significant. They also perform better than either naïve model as judged by actual returns. Their pooled mean forecast and actual 
Table 3: Two Linear Models

\begin{tabular}{|c|c|c|}
\hline Model & $\begin{array}{c}(3) \\
\text { VAR }\end{array}$ & $\begin{array}{c}(4) \\
\text { VECM }\end{array}$ \\
\hline \multicolumn{3}{|l|}{ (a) Model parameters } \\
\hline Dependent variable & $\Delta e_{j t}$ & $\Delta e_{j t}$ \\
\hline$\Delta e_{j, t-1}$ & $\begin{array}{c}0.1218^{* *} \\
(0.0267)\end{array}$ & $\begin{array}{c}0.1333^{* *} \\
(0.0268)\end{array}$ \\
\hline$i_{j, t-1}-i_{j, t-1}^{*}$ & $\begin{array}{c}0.2889 \\
(0.3529)\end{array}$ & $\begin{array}{c}0.7555^{* *} \\
(0.3506)\end{array}$ \\
\hline$\pi_{j, t-1}-\pi_{j, t-1}^{*}$ & $\begin{array}{c}0.2325 \\
(0.1603)\end{array}$ & $\begin{array}{c}0.1690^{* *} \\
(0.0047)\end{array}$ \\
\hline$q_{j, t-1}-\bar{q}_{j}$ & - & $\begin{array}{c}-0.0277^{* *} \\
(0.0047)\end{array}$ \\
\hline$R^{2}$, within & 0.0164 & 0.0319 \\
\hline$F$ & $\mathrm{~F}(3,2427)=8.66$ & $\mathrm{~F}(4,2426)=14.36$ \\
\hline Fixed effects & Yes & Yes \\
\hline Periods & 276 & 276 \\
\hline Currencies (relative to US\$) & 9 & 9 \\
\hline Observations & 2484 & 2484 \\
\hline \multicolumn{3}{|l|}{ (b) Trading performance $\dagger$} \\
\hline \multicolumn{3}{|l|}{ Predicted profits } \\
\hline Mean & 0.0038 & 0.0047 \\
\hline Std. dev. & 0.0033 & 0.0041 \\
\hline Skewness & 1.9779 & 1.7716 \\
\hline C.v. & 0.8566 & 0.8817 \\
\hline \multicolumn{3}{|l|}{ Forecast errors } \\
\hline Mean & 0.0007 & 0.0005 \\
\hline Std. dev. & 0.0294 & 0.0292 \\
\hline Skewness & -0.2196 & 0.0297 \\
\hline C.v. & 42.3705 & 53.5159 \\
\hline \multicolumn{3}{|l|}{ Actual profits } \\
\hline Mean & 0.0045 & 0.0052 \\
\hline Std. dev. & 0.0295 & 0.0294 \\
\hline Skewness & -0.1464 & 0.1195 \\
\hline C.v. & 6.5361 & 5.6245 \\
\hline
\end{tabular}

$\dagger$ Statistics for trading profits are net, monthly, pooled.

Note: C.v. = coefficient of variation $=$ ratio of standard deviation to mean. Standard errors in parentheses; ** $(*)$ denotes significant at the $95 \%(90 \%)$ confidence level. Estimation is by ordinary least squares.

returns are about half as high again. For actual returns, the coefficients of variation (the ratio of the sample variance to sample mean) are lower. Hence, their Sharpe ratios are higher, although still very small. For the VAR the monthly Sharpe is 0.15 (0.53 annualized), and for the VECM it is 0.18 (0.63 annualized). Even more notable, negative skews are much lower. VAR delivers an actual pooled return skew of -0.15 and the VECM actually turns in a slightly positive skew of 0.12. Statistically the VECM is preferred with $R^{2}$ and $F$-statistic twice as large, and the coefficient on the lagged real exchange rate highly significant. From a trading standpoint its performance is also a little better, with mean returns and Sharpe ratio up slightly. Still, 50 bps per month and an annualized Sharpe of 0.63 may be viewed as somewhat disappointing. However, the key finding is that when trades are made conditional on deviations from FEER, actual trading returns have a skew that is zero or mildly positive. 


\subsection{A Nonlinear Model}

Are these the best models we can find? We think not, due to the limitations of linear models. We present two arguments that force us to reckon with potential nonlinearities in the exchange rate dynamics.

The first possible reason for still disappointing performance in the VECM (Model 4) is that the model places excessively high weight on the raw carry signal emanating from the interest differential in some risky "high carry" circumstances. This may lead to occasional large losses, even if it is not enough to cause negative skew. Recall that naïve Model (2) placed zero weight on this signal as part of an exchange rate forecast, whereas here the weight is 0.76 . We conjecture that the true relationship may be nonlinear. Here we follow an emerging literature which suggests that deviations from UIP are corrected in a nonlinear fashion: that is, when interest differentials are large the exchange rate is more likely to move against the naïve carry trade, and in line with the efficient markets hypothesis (see, inter alia, Bilson 1981; Flood and M. P. Taylor 1996; Coakley and Fuertes 2001; Sarno, Valente and Leon 2006).

The second possible reason for disappointing performance might be related not to nonlinear UIP dynamics, but rather nonlinear PPP dynamics. Here it is possible that VECM places too little weight on the real exchange rate signal in some circumstances, e.g. when currencies are heavily over/undervalued and thus more prone to fall/rise in value. Here again, we build on an increasingly influential literature which point out that reversion to Relative PPP, largely driven by nominal exchange rate adjustment, is likely to be more rapid when deviations from FEER are large (see, inter alia, Obstfeld and Taylor 1997; Michael, Nobay and Peel 1997; Taylor, Peel, and Sarno 2001).

To sum up, past empirical findings suggest that the parameters of the Naïve ECM Model (2) may be expected to differ between regimes with small and large carry trade incentives, as measured by the lagged interest rate differential; and also to differ between regimes with small and large FEER deviations, as measured by the lagged real exchange rate. In addition to these arguments for a nonlinear model, the important role of the third moment in carry trade analyses also bolsters the case, given the deeper point made in the statistical literature that skewness cannot be adequately addressed outside of a nonlinear modeling framework (Silvennoinen, Teräsvirta and He, 2008).

To explore these possibilities we extend the framework further to allow for nonlinear dynamics. We first perform a test against nonlinearity of unknown form and find strong evidence of nonlinearity derived from the absolute magnitudes of interest differentials and real exchange rate deviations. We then implement a simple nonlinear threshold error correction model (TECM). For illustration, we employ an arbitrarily partitioned dataset with thresholds based on median absolute magnitudes.

Table 4 presents the nonlinearity tests using Model (4) in Table 3, the VECM model, where the candidate threshold variables are the absolute magnitudes of the lagged interest differential

$\left|i_{j, t-1}-i_{j, t-1}^{*}\right|$ and the lagged real exchange rate deviation $\left|q_{j, t-1}-\bar{q}_{j}\right|$. Although more specific nonlinearity tests tailored to particular alternatives would be more powerful, we are already able to 
Table 4: Nonlinearity Tests

\begin{tabular}{ll}
\hline \hline Hypothesis tests & Test statistic \\
\hline$H_{0}:$ Nonlinear in $\left|i_{j, t-1}-i_{j, t-1}^{*}\right|$ and $\left|q_{j, t-1}-\bar{q}_{j}\right|$ versus: & \\
\hline (a) $H_{1}:$ Nonlinear in $\left|q_{j, t-1}-\bar{q}_{j}\right|$ and & $F(44,2337)=4.28$ \\
$\quad$ linear in $\left|i_{j, t-1}-i_{j, t-1}^{*}\right|$ & $p=0.0000$ \\
\hline (b) $H_{2}:$ Nonlinear in $\left|i_{j, t-1}-i_{j, t-1}^{*}\right|$ and & $F(52,2337)=1.42$ \\
$\quad$ linear in $\left|q_{j, t-1}-\bar{q}_{j}\right|$ & $p=0.0262$ \\
\hline (c) $H_{3}:$ Linear in $\left|i_{j, t-1}-i_{j, t-1}^{*}\right|$ and & $F(96,2337)=28.04$ \\
$\quad$ linear in $\left|q_{j, t-1}-\bar{q}_{j}\right|$ & $p=0.0000$ \\
\hline
\end{tabular}

Notes: $p$ refers to the $p$-value for the LM test of the null of linearity against the alternative of nonlinearity based on a polynomial expansion of the conditional mean with the selected threshold arguments. See Granger and Teräsvirta (1993).

forcefully reject the null with generic forms of neglected nonlinearity by simply taking a polynomial expansion of the linear terms based on the threshold variables. This type of approach is often used in testing against linearity when a smooth transition regression (STAR) model is specified but it is clearly not limited to this alternative hypothesis (see Granger and Teräsvirta 1993). The regression test takes the form of an auxiliary regression involving polynomials of each variable, up to the fourth power.

The results in Table 4 show the hypothesis of linearity can be rejected at standard significance levels for specifications based on whether either or both threshold variables are considered simultaneously. Thus our VECM Model (4) in Table 3 appears to be misspecified, and so we are moved to develop a more sophisticated yet parsimonious nonlinear model. For illustration, we use a simple four-regime TECM, where the regimes are delineated by thresholds values arbitrarily taken to be the median levels of the absolute values of the regressors $I_{j, t-1}=\left|i_{j, t-1}-i_{j, t-1}^{*}\right|$ and $Q_{j, t-1}=\left|q_{j, t-1}-\bar{q}_{j}\right|$. For simplicity these thresholds will be denoted by $\theta_{i}$ and $\theta_{q}$ respectively.

Estimates of this model, denoted Model (5) in Table 5, show that from both an econometric and a trading standpoint, the performance of the nonlinear model is outstanding. It also accords with many widely recognized state-contingent FX market phenomena.

We see from Panel (a) in Table 5 that the estimated model coefficients differ sharply across the four regimes. The null of no differences across regimes is easily rejected. In Column 1 of Table 5 we see that the model performs rather poorly in the regime where both interest differentials and real exchange rate deviations are small. Still, there is weak evidence for a self-exciting dynamic with a very strong forward bias: the coefficient on the interest differential is large $(+2.5)$ consistent with traders attracted by carry incentives bidding up the higher yield currency. However, for small interest differentials, we can see from Column 3 in Table 5 that this effect disappears, once large real exchange rate deviations emerge. Still, the fit of the model remains quite poor in Column 3 also.

In Column 2 of Table 5, where the interest differential is above median, this self-exciting property is also manifest clearly, with a coefficient of +1.8 that is statistically significant at the $5 \%$ level. The results strongly suggest that wide interest differentials take exchange rates "up the stairs" on a gradual appreciation away from fundamentals. Of course, for given price levels or inflation rates, such dynamics quickly cumulate in ever-larger real exchange rate deviations, 
Table 5: Noninear Model

\begin{tabular}{|c|c|c|c|c|}
\hline \multirow{2}{*}{$\begin{array}{l}\text { Model } \\
\text { (a) Model parameters } \\
\text { (by regime) }\end{array}$} & \multicolumn{4}{|c|}{$\begin{array}{c}(5) \\
\text { NECM }\end{array}$} \\
\hline & $\begin{aligned} Q_{j, t-1} & <\theta_{q} \\
I_{j, t-1} & <\theta_{i}\end{aligned}$ & $\begin{array}{c}Q_{j, t-1}<\theta_{q} \\
I_{j, t-1}>\theta_{i}\end{array}$ & $\begin{aligned} Q_{j, t-1} & >\theta_{q} \\
I_{j, t-1} & <\theta_{i}\end{aligned}$ & $\begin{array}{c}Q_{j, t-1}>\theta_{q} \\
I_{j, t-1}>\theta_{i}\end{array}$ \\
\hline Dependent variable & $\Delta e_{j t}$ & $\Delta e_{j t}$ & $\Delta e_{j t}$ & $\Delta e_{j t}$ \\
\hline$\Delta e_{j, t-1}$ & $\begin{array}{c}0.0637 \\
(0.0417)\end{array}$ & $\begin{array}{c}0.1228^{* *} \\
(0.0494)\end{array}$ & $\begin{array}{c}0.1029 * \\
(0.0574)\end{array}$ & $\begin{array}{c}0.2027^{* *} \\
(0.0567)\end{array}$ \\
\hline$i_{j, t}-i_{j, t-1}^{*}$ & $\begin{array}{c}2.5033^{* *} \\
(1.1577)\end{array}$ & $\begin{array}{c}1.7790^{* *} \\
(0.6379)\end{array}$ & $\begin{array}{c}0.8707 \\
(1.3585)\end{array}$ & $\begin{array}{c}-0.5734 \\
(0.7811)\end{array}$ \\
\hline$\pi_{j t}-\pi_{j t}^{*}$ & $\begin{array}{c}0.6731 \\
(0.4101)\end{array}$ & $\begin{array}{c}0.3836 \\
(0.3880)\end{array}$ & $\begin{array}{c}-0.5269 \\
(0.3945)\end{array}$ & $\begin{array}{c}0.1331 \\
(0.2173)\end{array}$ \\
\hline$q_{j t}-\bar{q}_{j}$ & $\begin{array}{c}-0.0572^{* *} \\
(0.0011)\end{array}$ & $\begin{array}{c}-0.0564^{* *} \\
(0.0265)\end{array}$ & $\begin{array}{c}-0.0146^{* *} \\
(0.0072)\end{array}$ & $\begin{array}{c}-0.0364^{* *} \\
(0.0077)\end{array}$ \\
\hline \multicolumn{5}{|l|}{$R^{2}$, within } \\
\hline$F$ & $\begin{array}{c}\mathrm{F}(4,642) \\
=4.63\end{array}$ & $\begin{array}{c}\mathrm{F}(4,549) \\
=4.29\end{array}$ & $\begin{array}{c}\mathrm{F}(4,554) \\
=1.90\end{array}$ & $\begin{array}{c}\mathrm{F}(4,641) \\
=8.60\end{array}$ \\
\hline Fixed effects & Yes & Yes & Yes & Yes \\
\hline Periods & 276 & 276 & 276 & 276 \\
\hline Currencies (relative to US $\$$ ) & 9 & 9 & 9 & 9 \\
\hline Observations (by regime) & 655 & 562 & 567 & 654 \\
\hline \multicolumn{5}{|l|}{ (b) Trading performance $\dagger$} \\
\hline \multicolumn{5}{|l|}{ Predicted profits } \\
\hline Mean & \multicolumn{4}{|c|}{0.0057} \\
\hline Std. dev. & \multicolumn{4}{|c|}{0.0052} \\
\hline Skewness & \multicolumn{4}{|c|}{2.1205} \\
\hline C.v. & \multicolumn{4}{|c|}{0.9153} \\
\hline \multicolumn{5}{|l|}{ Forecast errors } \\
\hline Mean & \multicolumn{4}{|c|}{-0.00002} \\
\hline Std. dev. & \multicolumn{4}{|c|}{0.0289} \\
\hline Skewness & \multicolumn{4}{|c|}{0.2573} \\
\hline C.v. & \multicolumn{4}{|c|}{-1626.59} \\
\hline \multicolumn{5}{|l|}{ Actual profits } \\
\hline Mean & \multicolumn{4}{|c|}{0.0057} \\
\hline Std. dev. & \multicolumn{4}{|c|}{0.0293} \\
\hline Skewness & \multicolumn{4}{|c|}{0.3674} \\
\hline C.v. & \multicolumn{4}{|c|}{5.1769} \\
\hline
\end{tabular}

$\uparrow$ Statistics for trading profits are net, monthly, pooled.

Note: C.v. = coefficient of variation $=$ ratio of standard deviation to mean. Standard errors in parentheses; $* *(*)$ denotes significant at the $95 \%(90 \%)$ confidence level. Estimation is by ordinary least squares.

moving the model's regime to Column 4 in Table 5, where the fit of the model is best, as shown by a high $R^{2}$ and $F$-statistic. And here the dynamics dramatically change such that the exchange rate can rapidly descend "down the elevator": the lagged real exchange rate carries a highly significant convergence coefficient of $3.6 \%$ per month, working against previous appreciation of the target currency, and reverse exchange rate momentum then snowballs, with the lagged exchange rate change carrying a now significant and large coefficient of 0.2 .

In addition to being the preferred model based on statistical tests, does the nonlinear TECM Model (5) in Table 5 deliver better trading strategies? Panels (b)-(d) in that table suggest so. Compared to the VECM Model (4) in Table 3, predicted and actual pooled profits are higher still, 
and nearing 60 bps per month. The pooled actual returns Sharpe ratio is now 0.19 monthly $(0.67$ annualized). This model's annual Sharpe ratio is the best yet, although it is still well below the annual 1.0 Sharpe ratio benchmark commonly cited as the relevant hurdle for investors. Finally we note that the TECM actual returns are strongly positively skewed: again, crashes are largely avoided.

\subsection{Portfolio Strategies}

The performance of a pooled set of trades for the naïve, linear, and nonlinear models shows how model performance can be improved. But these statistics bear no relation to actual market activity. In reality, traders do not pick a random currency pair each period in which to trade. Instead, currency funds invest in a portfolio of currencies. This allows funds to take advantage of gains from diversification: standard statistical intuition (cf. the Central Limit Theorem) tells us that variance and skewness can be curtailed by taking an average of draws that are imperfectly correlated. ${ }^{20}$ (Here, for example, $N=9$ so the standard deviation of profits for equal-weight portfolio trades will be one third that of the underlying set of pooled trades.)

As a practical matter for many trading strategies studied in the academic literature, and some used in practice, the portfolio choice is restricted - for reasons of simplicity, comparability, diversification and transparency. ${ }^{21}$ The simplest restriction is to employ simple equal-weight portfolios where a uniform bet of size $\$ 1 / N$ is placed on each of $N$ FX-USD pairs, so that the only forecast-based decision is the binary long-short choice for each pair in each period. Granted, lifting this restriction to allow adjustable portfolio weights must, ipso facto, allow even better trading performance, at least on backtests. But from our standpoint of presenting a puzzle - rejecting the null of the efficient market hypothesis, and showing a strategy with high returns and Sharpes, and low skewness-meaningful forecasting success even when restricted to an equal-weight portfolio is evidence enough to support our story.

Table 6 illustrates the gains from diversification strategies and shows how these gains deliver very promising returns in cases where our FEER based models are employed. In each panel we report mean, standard deviation, skewness, coefficient of variation, and annual Sharpe ratios for the naïve models, the linear models, and the nonlinear model. (Annual Sharpe is computed as monthly Sharpe times $\sqrt{12}$.) In all cases the U.S. dollar is the base currency, as before.

Here we hypothetically wager $\$ 1 / \mathrm{N}$ on each currency trade, for the $\mathrm{N}$ currencies, with the long-short direction for each currency given by the model's predicted return. This is called the equal-weight portfolio. For these portfolios we construct summary statistics as before, plus an annual Sharpe ratio. The performance of the portfolio-based trading strategies is revealing. It is clear that some of the advantage of the VAR and the VECM models (3) and (4) over the naïve models starts to wane once many currencies are traded, but the nonlinear TECM retains some clear advantages by better avoiding currencies with high unconditional crash potential.

Consider first the Naïve Model (1) in Table 2 and the VAR Model (3) in Table 3, without any

\footnotetext{
${ }^{20}$ A numerical illustration is provided by Burnside, Eichenbaum and Rebelo (2008).

21 Indeed, recent research suggests that variable "optimal" portfolio weights may not deliver meaningful gains over the simple $1 / N$ strategy (DeMiguel, Garlappi, and Uppal 2009).
} 
Table 6: Portfolio Performance

Monthly trading profits for equal-weight portfolios

\begin{tabular}{|c|c|c|c|c|c|}
\hline & $\begin{array}{c}(1) \\
\text { Naïve }\end{array}$ & $\begin{array}{c}(2) \\
\text { Naïve } \mathrm{ECM}\end{array}$ & $\begin{array}{c}(3) \\
\text { VAR }\end{array}$ & $\begin{array}{c}(4) \\
\end{array}$ & (5) \\
\hline Observations & 276 & 276 & 276 & 276 & 276 \\
\hline Mean & 0.0026 & 0.0034 & 0.0045 & 0.0052 & 0.0057 \\
\hline Std. dev. & 0.0154 & 0.0163 & 0.0159 & 0.0169 & 0.0155 \\
\hline Skewness & -1.8793 & 0.2472 & -0.1019 & 1.0994 & 1.0704 \\
\hline Kurtosis & 11.3818 & 3.9371 & 4.0890 & 8.1154 & 8.1316 \\
\hline C.v. & 5.8764 & 4.8622 & 3.5318 & 3.2354 & 2.7357 \\
\hline Sharpe ratio, annualized* & 0.5895 & 0.7125 & 0.9808 & 1.0707 & 1.2663 \\
\hline
\end{tabular}

* Statistics for trading profits are net, monthly, except for annualized Sharpe ratio.

Note: C.v. = coefficient of variation $=$ ratio of standard deviation to mean .

real FEER fundamental. Gains from diversification are obvious right away as compared with the pooled data presented earlier. Under equal-weight portfolios, the Naïve Model attains an annual Sharpe of 0.59 but the VAR now has an annual Sharpe of 0.98 . However, these portfolio strategies are still rather undesirable given their low returns of 26-34 bps per month and negative skew.

In contrast, the linear models of the Naïve ECM Model (2) in Table 2 and the VECM Model (4) in Table 3 do a very good job in the portfolio setting in purging unwanted skewness from actual returns. The Naïve ECM has weak positive skew, and VECM has weak negative skew. Returns are 45-52 bps per month, and the annualized Sharpe ratios are 0.71 and 1.07 respectively, thus clearing the mythical 1.0 hurdle.

The superiority of the TECM model is now very clear, as shown by the final column of Table 6. In equal weight form, it outshines all other models on mean return (57 bps per month) and annualized Sharpe $(1.27) \cdot{ }^{22,23}$

\subsection{Exploring the Performance Improvements}

We now start to examine why our proposed model refinements generate improved performance and, as we do so, we shall begin to shift the focus of the analysis to out-of-sample performance, which will be the centerpiece of our empirical work in section 3 .

We look at both in and out-of-sample evidence, and the sample reserved for out-of-sample evaluation was chosen to run from January 2004 to December 2008. For these purposes, one stepahead forecasts are generated, one at a time, with a rolling window that begins with the January 1986 observation and finishes with the December 2003 observation. Table 7 shows that the model refinements do very little to increase the ability of the trader to pick a profitable direction for a trade over and above the Naïve carry strategy. In sample, the random walk exchange-rate model

\footnotetext{
22 Even if the entire portfolio churns once per month, which it does not, and assuming typical G10 bid-ask spreads of 2 bps for a round trip, these returns would be 55 bps and 82 bps, respectively, with miniscule downward revisions in the Sharpe ratios even after allowance for transaction costs.

23 Further tweaks are possible to enhance performance even further. If equal weights are replaced by weights proportional to the signal strength, the TECM model achieves returns ( 84 bps per month) and an annualized Sharpe ratios (1.48) that are even more impressive, without negative skew. The improvements occur because the linear weighting allows the model to re-weight towards more high risk/return trades with negative skew, without turning the overall skew significantly negative.
} 
Table 7: Fraction of Profitable Trading Positions Correctly Called (\%)

\begin{tabular}{lccccc}
\hline \hline (a) In sample & & & & & \\
\hline Australia & Naïve & Naïve ECM & VAR & VECM & TECM \\
Canada & 62.9 & 57.5 & 56.6 & 55.5 & 55.9 \\
Germany & 57.8 & 52.0 & 56.6 & 55.9 & 54.8 \\
Japan & 52.0 & 53.1 & 55.9 & 54.0 & 56.3 \\
New Zealand & 58.2 & 53.8 & 61.0 & 59.9 & 56.3 \\
Norway & 63.3 & 59.3 & 62.1 & 57.7 & 58.8 \\
Sweden & 57.1 & 55.3 & 57.4 & 56.6 & 58.1 \\
Switzerland & 62.7 & 50.6 & 66.2 & 66.2 & 62.4 \\
UK & 53.8 & 54.5 & 58.1 & 55.1 & 58.1 \\
& 53.1 & 54.9 & 49.3 & 53.3 & 53.9 \\
\hline (b) Out of sample & 57.9 & 54.6 & 58.1 & 57.1 & 57.1 \\
\hline & & & & & \\
Australia & Naïve & Naïve ECM & VAR & VECM & TECM \\
Canada & 55.0 & 48.3 & 53.3 & 45.0 & 58.3 \\
Germany & 43.3 & 51.7 & 50.0 & 46.7 & 51.7 \\
Japan & 45.0 & 46.7 & 48.3 & 51.7 & 45.0 \\
New Zealand & 56.7 & 56.7 & 65.0 & 66.7 & 56.7 \\
Norway & 61.7 & 60.0 & 60.0 & 60.0 & 60.0 \\
Sweden & 46.7 & 46.7 & 58.3 & 58.3 & 48.3 \\
Switzerland & 53.3 & 53.3 & 56.7 & 60.0 & 60.0 \\
UK & 53.3 & 55.0 & 53.3 & 53.3 & 55.0 \\
& 45.0 & 50.0 & 51.7 & 51.7 & 45.0 \\
\multicolumn{1}{c}{ Pooled } & 51.1 & 52.0 & 55.2 & 54.8 & 53.3 \\
\hline
\end{tabular}

Note: In sample is 1987 to 2008 , out of sample is 2004 to 2008 recursive.

gets the direction of $58 \%$ of trades right, but what is striking is that the other models do no better. The TECM also achieves $58 \%$. Out of sample, the findings are similar: the Naïve model got the direction right $51 \%$ of the time, the TECM $53 \%$. So what is so great about the refined models?

The answer is given in Table 8 and explored in much more detail in the next section. It is not the ability to more often pick the right direction of trades that matters; it is the ability to pick the right direction on trades that result in large gains or losses. In other words, there is a huge difference between a currency forecasting model with good overall fit, and one that makes money. This is a classic example of being careful not to judge models by an inappropriate criterion, or neglecting to note that a good model in this context is one that "fits where it matters" in the data space (Hand and Vinciotti 2003; Jordà and Taylor 2009).

For simplicity, Table 8 compares just the Naïve and TECM models. In-sample (panel a) we find that over 2438 pooled trades, the two models agreed on direction 1547 times and disagreed 891 times. When in agreement, returns were 65 bps per month, Annual Sharpe was 0.83 and skew was -0.23 . The worst trade lost $11 \%$ in a month, the best gained $12 \%$. But when the models took opposite sides, the differences were stark. The Naïve model collected negative returns of $42 \mathrm{bps}$, the TECM just the opposite. Annual Sharpes were -0.44 versus 0.44. Skew was -0.97 versus 0.97. Naïve suffered a worst trade of $17 \%$, but the TECM had that on the plus side. TECM's worst month was only a $7 \%$ loss, and that was Naïve's best. These results explain why overall, the TECM did better: it avoided crashes, and when extreme returns were likely it was better able to pick the right side of the trade. Overall returns in TECM were 57 versus 26 bps per month for 
Table 8: When Does the TECM Model Outperform the Naïve Model?

\begin{tabular}{|c|c|c|c|c|c|c|c|}
\hline$\overline{\overline{\text { (a) In sample }}}$ & $\overline{\mathrm{N}}$ & "mean & s.d. & Sharpe & skew & $\overline{\mathrm{m} \min }$ & $\overline{\max }$ \\
\hline \multicolumn{8}{|l|}{ All trades pooled } \\
\hline Naïve & 2438 & 0.0026 & 0.0297 & 0.3032 & -0.6926 & -0.1773 & 0.1180 \\
\hline TECM & 2438 & 0.0057 & 0.0293 & 0.6691 & 0.3674 & -0.1100 & 0.1773 \\
\hline \multicolumn{8}{|l|}{ Models agree } \\
\hline Naïve & 1547 & 0.0065 & 0.0270 & 0.8345 & -0.2272 & -0.1100 & 0.1180 \\
\hline TECM & 1547 & 0.0065 & 0.0270 & 0.8345 & -0.2272 & -0.1100 & 0.1180 \\
\hline \multicolumn{8}{|l|}{ Models disagree } \\
\hline Naïve & 891 & -0.0042 & 0.0329 & -0.4387 & -0.9740 & -0.1773 & 0.0744 \\
\hline TECM & 891 & 0.0042 & 0.0330 & 0.4427 & 0.9694 & -0.0744 & 0.1773 \\
\hline (b) Out of sample & $\mathrm{N}$ & mean & s.d & Sharpe & skew & $\min$ & $\max$ \\
\hline \multicolumn{8}{|l|}{ All trades pooled } \\
\hline Naïve & 539 & -0.0025 & 0.0315 & -0.2721 & -1.0580 & -0.1773 & 0.1038 \\
\hline TECM & 539 & 0.0028 & 0.0315 & 0.3033 & 0.7006 & -0.1056 & 0.1773 \\
\hline \multicolumn{8}{|l|}{ Models agree } \\
\hline Naïve & 373 & 0.0002 & 0.0278 & 0.0254 & -0.3700 & -0.1056 & 0.1038 \\
\hline TECM & 373 & 0.0002 & 0.0278 & 0.0254 & -0.3700 & -0.1056 & 0.1038 \\
\hline \multicolumn{8}{|l|}{ Models disagree } \\
\hline Naïve & 166 & -0.0085 & 0.0379 & -0.7765 & -1.4338 & -0.1773 & 0.0736 \\
\hline TECM & 166 & 0.0085 & 0.0379 & 0.7765 & 1.4338 & -0.0736 & 0.1773 \\
\hline
\end{tabular}

Note: In sample is 1987 to 2008 , out of sample is 2004 to 2008 recursive. The Sharpe ratio is annualized. Other statistics are monthly.

Naïve, Annual Sharpe was 0.67 versus 0.30, and skew was +0.37 versus -0.69 .

The out-of-sample results in Table 8 panel (b) apply to the period of the credit crunch and great carry trade crash of 2008 . These results only amplify the point further. Mean returns were not that different here, 28 versus -25 bps per month but they were at least up for TECM. Sharpe was +0.30 versus -0.27 . Skew was the dramatically different factor in the crisis period: +0.70 for TECM versus -1.17 for the Naïve model.

To sum up, after several stages of refinement, our preferred TECM model surmounts the objections usually raised to justify excess returns to carry trades. The crudest, naïve long-short carry trade strategies, even with currency diversification, deliver Sharpe ratios well below investors' benchmark 1.0 threshold and crash-ridden returns displaying marked negative skew. But by conditioning on the real exchange rate and allowing for nonlinearity, our TECM portfolios deliver high returns with a Sharpe ratio $25 \%-50 \%$ above the conventional hurdle for an unexploited risky arbitrage opportunity.

\section{Predictive Ability Evaluation}

Is this all too good to be true? Out-of-sample predictive ability testing is the gold standard by which the success or failure of many models in economics is judged. The literature on the ability to predict exchange rates spawned by Meese and Rogoff (1983) has been particularly savage on the field: time and again the invincible random walk has emerged victorious against an onslaught of ever more sophisticated economic/econometric models of the exchange rate. The models investigated in the previous section are promising suitors but they must now face rigorous 
scrutiny.

The approach that we pursue in this section builds on some standard predictive ability measures and brings in other techniques that are quite new in economics. Moreover, rather than just evaluating the ability to predict exchange rates per se, we are interested in evaluating a model's ability to generate attractive profits that have high Sharpe ratios and low skewness.

Recall our definition of ex-post nominal excess returns of a long FX position (with currency index $j$ now suppressed for clarity):

$$
m_{t+1}=\Delta e_{t+1}+\left(i_{t}^{*}-i_{t}\right)
$$

which we labeled momentum and let $\widehat{m}_{t+1}$ denote the one-period ahead forecast. Since $\left(i_{t}^{*}-i_{t}\right)$ is known at time $t$, then the only source of uncertainty comes from the prediction of $\Delta e_{t+1}$. In practice, the position an actual trader takes (i.e., determining which currency to borrow in and which to invest in) depends on the sign of $\widehat{m}_{t+1}$ for which we define the dichotomous variable $\widehat{d}_{t+1}$. This variable takes the value of 1 if $\widehat{m}_{t+1}>0$ and -1 otherwise, so that realized returns can be defined as

$$
\widehat{\mu}_{t+1}=\widehat{d}_{t+1} m_{t+1} .
$$

Setting the forecasting problem up as a binary choice or direction problem makes sense on a couple of dimensions. First, as a statistical matter, making successful continuous exchange rate (and hence, return) forecasts is a harder challenge, as those working in the Meese-Rogoff tradition have shown; but a directional forecast sets a lower bar, one that recent work suggests could be surmountable (Cheung, Chinn, and Garcia Pascual 2005). Second, it is all that is needed in the case of equal-weight currency portfolios. Thirdly, directional forecasting is important for traders. Like other funds, currency strategies face the risk of redemptions or closure if negative returns are frequent and/or large. It is nice to pick the bigger winners, rather than just small ones, but not if the strategy risks blowing up. The point is only amplified when funds are leveraged. Thus from a trader's point of view, what is often most important is the ability to correctly predict the profitable direction of the carry trade and for this reason we introduce methods designed to evaluate a model's ability to correctly classify the data according to direction.

In this section we examine the directional predictive ability of our preferred models in two ways. First, we evaluate the quality of the binary signal itself using new techniques from signal detection theory. We then evaluate the performance of trading strategies based on the binary signal, using loss-function methods that can go beyond the prevalent RMSE criterion and instead be adapted to metrics of investment performance of interest to traders, like returns, Sharpe, and skewness.

\subsection{Hits and Misses: The ROC Curve}

Forecasts of a binary outcome are called classifiers. The biostatistics and engineering literatures provide techniques, rarely used in economics, for the statistical evaluation of models for classification (see Pepe, 2003 for a survey). Specifically, the receiver operating characteristic (ROC) curve 
characterizes the quality of a forecasting model and its ability to anticipate correctly the occurrence and non-ocurrence of pre-defined events. ${ }^{24}$ For greater detail, we refer readers to another paper where we discuss and develop ROC techniques to evaluate investment performance (Jordà and Taylor 2009).

In our problem the directional outcome variable is $d_{t+1}=\operatorname{sign}\left(m_{t+1}\right) \in\{-1,1\}$, the ex-post profitable direction of the currency investment. Let the variable $\widehat{\delta}_{t+1}$ to be a scoring classifier such that for a given threshold $c, \widehat{\delta}_{t+1}>c$ is taken to indicate $\widehat{d}_{t+1}=1$, and $\widehat{\delta}_{t+1} \leq c$ corresponds to $\widehat{d}_{t+1}=-1$ instead. Our classifier will be the predictions of the conditional means obtained with the models in Tables $2-5$, so that $\widehat{\delta}_{t+1}=\widehat{m}_{t+1}$ but in what follows we maintain the more generic notation $\widehat{\delta}_{t+1}$.

Let $T P(c)$ denote the true positive rate defined as $P\left[\widehat{\delta}_{t+1}>c \mid d_{t+1}=1\right]$, sometimes also called sensitivity or recall rate, and in the more familiar Neyman-Pearson nomenclature, 1 minus the Type II error, or the power of the test (the test here being the ability to correctly identify $d_{t+1}$ with $h\left(\widehat{\delta}_{t+1}\right)$, for any strictly monotonic function $\left.h().\right)$. Let $F P(c)$ denote the false positive rate defined as $P\left[\widehat{\delta}_{t+1}>c \mid d_{t+1}=-1\right]$ which is 1 minus the specificity or the Type I error, or the size of the test. Then the ROC curve is defined as the plot of $T P(c)$ against $F P(c)$ for values of $c \in(-\infty, \infty)$. Notice that when $c=\infty, T P(c)=F P(c)=0$ and when $c=-\infty$ then $T P(c)=F P(c)=1$ so that the ROC curve can be displayed in $[0,1] \times[0,1]$ space.

The 45-degree diagonal line corresponds to the ROC curve of a uninformative classifier, where, for any given observation, at any threshold, there is a 50-50 chance of correctly classifying the direction of trade. In this context, the 45-degree line corresponds to the natural null of the efficient markets hypothesis: on average, profitable trades cannot be predicted better than a coin toss and the classifier contains no information at any threshold. This is a natural benchmark in our analysis. Intuitively, the "better" a classifier is, the closer the ROC curve is to the ideal classifier that hugs the left and top edges of the unit square (and the further away it is from the 45-degree line). We now apply a formal test based on this intuition.

The area under the curve (AUC) measures the probability that the classifier for an observation whose outcome is $d_{t+1}=1$ attains a higher value than that for an observation whose outcome is $d_{t+1}=-1$, that is $P\left[\widehat{\delta}_{t+1}^{+}>\widehat{\delta}_{t+1}^{-}\right]$and where the superscript denotes the sign of the true outcome. Thus, the AUC ranges from 0.5 to 1 , since for a simple coin toss the probability described previously would be 0.5 . (Should any classifier deliver an AUC less than 0.5 , its forecast could simply be inverted!) ${ }^{25}$

As an illustration using our data, Figure 1 shows a ROC graph. The ROC is displayed for the case of directional forecasts for the New Zealand dollar only, for the preferred TECM model, with

\footnotetext{
24 The origin of the ROC curve can be traced back to radar signal detection theory developed in the 1950s and 1960s (Peterson and Birdsall, 1953), and its potential for medical diagnostic testing was recognized as early as 1960 (Lusted, 1960). More recently, ROC analysis has been introduced in psychology (Swets, 1973), in atmospheric sciences (Mason, 1982), and in the machine learning literature (Spackman, 1989).

${ }^{25}$ The AUC statistic is closely related to the Wilcoxon-Mann-Whitney (WMW) $U$ statistic of equality between classifiers by the relation: $U=n_{+} n_{-}(1-A U C)$ where $n_{+}$refers to those observations for which $d_{t+1}=1, n_{-}$ refers to those observations for which $d_{t+1}=-1$, and $U$ is asymptotically normal. Thus, AUC provides a second and more convenient non-parametric test for the quality of a classifier with respect to the coin toss and, in practice, it is the summary statistic commonly reported in ROC analysis. The $U$ statistic is also known to be robust to heteroskedasticity (Conover 1999).
} 
Figure 1: A ROC Curve Example: New Zealand Dollar

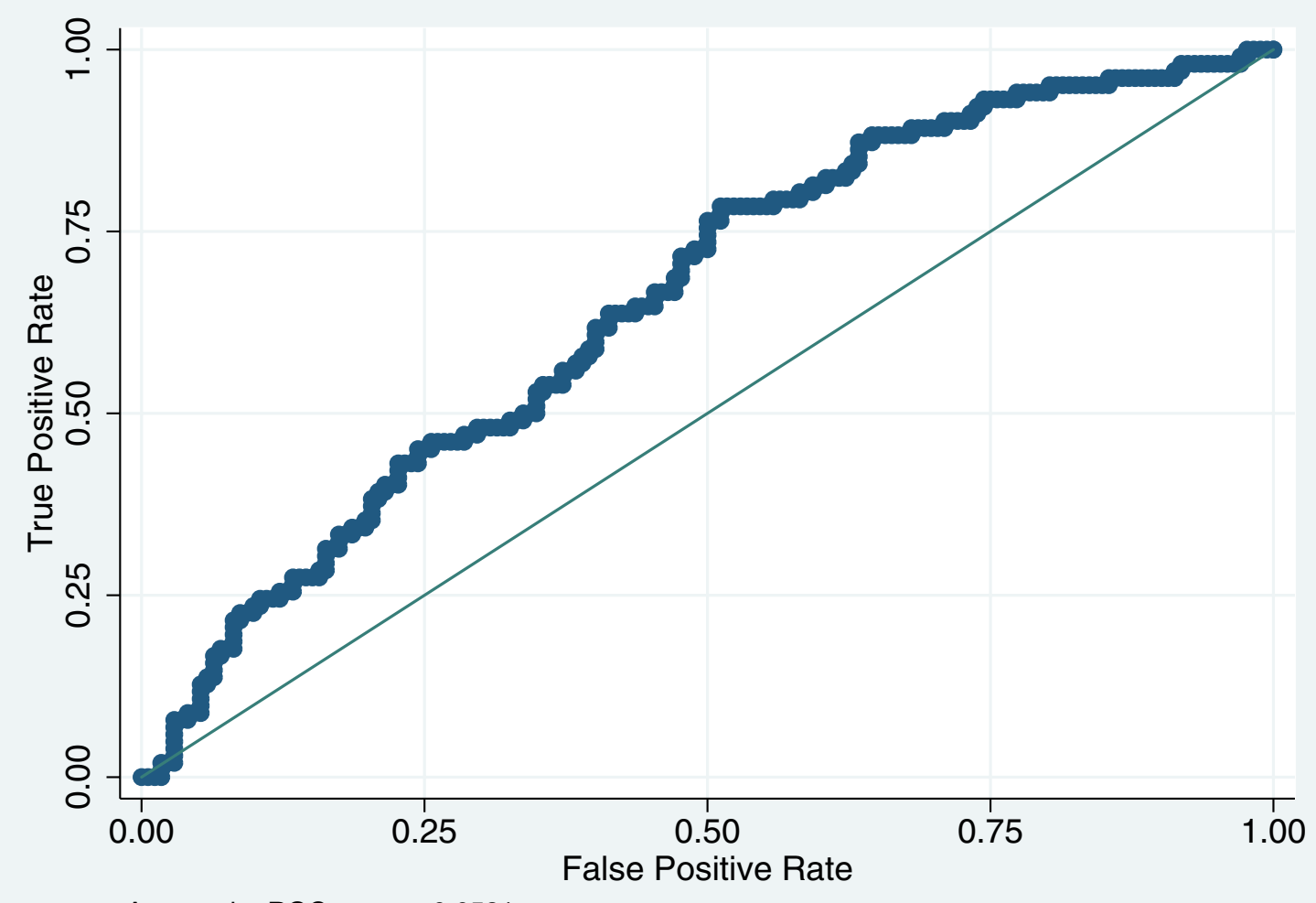

Area under ROC curve $=0.6531$

Notes: In-sample predictions using TECM Model. Sample: Apr. 1986 to Dec. 2008. Area under the curve for this case: $\mathrm{AUC}=0.6531$ (s.e. $=0.0335, z=4.5673, p=0.0000$ ).

in-sample predictions. In this case, the AUC is about 0.65 and statistically significantly different from the coin toss with a $p$-value of 0.0000 . Obviously, we could generate a ROC graph for each model, country and sample - 90 graphs in all - but this is clearly impractical. Instead we pool the data, and Table 9 shows the pooled AUC, in- and out-of-sample, for a concise summary. All models appear informative for the in sample case; but the results are weaker for the naïve models in the out-of-sample case. However, the VAR, VECM and TECM all deliver impressive out-ofsample $z$-scores that exceed 2 surmount the $5 \%$ significance level to reject the efficient markets null. By these criteria, G10 currency returns are clearly forecastable at a one month horizon, in a directional sense, at very high levels of statistical significance using our modeling approach.

\subsection{Gains and Losses: The Return-Weighted ROC* Curve}

The ROC analysis shows that our model is a good classifier of optimal direction. However, correctly classifying the direction of the trades without regard for the returns or losses generated by the classification is insufficient. For example, Tables 7 and 8 showed that although the TECM model does not pick winners any better than some simpler specifications, it is able to avoid large losses 
Table 9: Area Under the ROC Curve

\begin{tabular}{lcccc}
\hline \hline Model & AUC & s.e. & $z$-score & $p$-value \\
\hline (a) In Sample & & & & 0.0000 \\
Naïve & 0.5905 & 0.0115 & 7.85 & 0.0000 \\
Naïve ECM & 0.5604 & 0.0116 & 5.19 & 0.0000 \\
VAR & 0.5996 & 0.0115 & 8.67 & 0.0000 \\
VECM & 0.5935 & 0.0115 & 8.11 & 0.0000 \\
TECM & 0.6084 & 0.0114 & 9.47 & 0.4949 \\
(b) Out of sample & & & 0.68 & 0.3236 \\
Nä̈ve & 0.5170 & 0.0249 & 0.99 & 0.0081 \\
Naïve ECM & 0.5245 & 0.0249 & 2.65 & 0.0015 \\
VAR & 0.5654 & 0.0247 & 3.17 & 0.0284 \\
VECM & 0.5778 & 0.0246 & 2.19 & 15 \\
TECM & 0.5541 & 0.0247 & 2004 & $\mathrm{~A}$ \\
\hline
\end{tabular}

Notes: In sample is 1987 to 2008, out of sample is 2004 to 2008 with recursive estimation. The AUC statistic is a Wilcoxon-Mann-Whitney $U$-statistic with asymptotic normal distribution and its value ranges from 0.5 under the null to a maximum of 1 (an ideal classifier). See Jordà and Taylor (2009).

responsible for negative skewness in the distribution of returns. Thus, a classifier that correctly pinpoints 10 trades with low returns but misses a key trade that generates a devastating loss will be less desirable than a classifier that is equally accurate on average but correctly classifies the large events.

For this reason, Jordà and Taylor (2009) introduce a novel refinement to the construction of the ROC curve that accounts for the relative profits and losses of the classification mechanism. ${ }^{26}$ We proceed in the spirit of gain-loss measures of investment performance (Bernardo and Ledoit 2000) by attaching weights to a given classifier's upside and downside outcomes in proportion to observed gains and losses. This alternative performance measure will give little weight to right or wrong bets when the payoffs are small; but when payoffs are large it will penalize classifiers for picking trades that turn out to be big losers, and reward them for picking big winners.

To keep the new curve normalized to the unit square, consider all the trades where "long FX" was the ex-post correct trade to have made. The maximum gain from classifying all these trades correctly with $\widehat{d}_{t+1}=1$ would be

$$
B_{\max }=\sum_{d_{t+1}=1} m_{t+1}
$$

Now consider all the trades where "short FX" was the ex-post correct trade to have made. Similarly, the maximum loss from misclassification of these trades, and going long in them, would be

$$
C_{\max }=\sum_{d_{t+1}=-1} m_{t+1}
$$

We can now redefine, or rescale, the true positive and false positive rates $T P(c)$ and $F P(c)$ in terms of the upside and downside returns $m$ actually achieved, relative to the maximally attainable gains and losses thus defined. For any given threshold $c$, this leads to new statistics as follows:

\footnotetext{
${ }^{26}$ A similar improvement to ours is the instance-varying ROC curve described in Fawcett (2006).
} 
Table 10: Area Under the Return-Weighted ROC* Curve

\begin{tabular}{lcccc}
\hline \hline Model & AUC $^{*}$ & s.e. & $z$-score & $p$-value \\
\hline (a) In Sample & & & & \\
Naïve & 0.5690 & 0.0116 & 5.94 & 0.0000 \\
Naïve ECM & 0.6060 & 0.0114 & 9.26 & 0.0000 \\
VAR & 0.6291 & 0.0113 & 11.42 & 0.0000 \\
VECM & 0.6496 & 0.0112 & 13.41 & 0.0000 \\
TECM & 0.6769 & 0.0109 & 16.21 & 0.0000 \\
\hline (b) Out of sample & & & 0.0087 \\
Naïve & 0.4355 & 0.0246 & -2.62 & 0.8747 \\
Naïve ECM & 0.4961 & 0.0249 & -0.16 & 0.0034 \\
VAR & 0.5720 & 0.0246 & 2.92 & 0.0000 \\
VECM & 0.6052 & 0.0243 & 4.37 & 0.0002 \\
TECM & 0.5912 & 0.0244 & 3.73 & TUC
\end{tabular}

Notes: In sample is 1987 to 2008 , out of sample is 2004 to 2008 with recursive estimation. The AUC* statistic is a Wilcoxon-Mann-Whitney $U$-statistic with asymptotic normal distribution and its value ranges from 0.5 under the null to a maximum of 1 (an ideal classifier). See Jordà and Taylor (2009).

$$
T P^{*}(c)=\frac{\sum_{\widehat{d}_{t+1}=1 \mid d_{t+1}=1} m_{t+1}}{B_{\max }} ; \quad \text { and } \quad F P^{*}(c)=\frac{\sum_{\widehat{d}_{t+1}=1 \mid d_{t+1}=-1} m_{t+1}}{C_{\max }}
$$

The plot of $T P^{*}(c)$ versus $F P^{*}(c)$ is then, by construction, limited to the unit square, and generates what we term a returns-weighted $R O C$ curve, which is denoted the ROC* curve. Associated with the ROC* curve is a corresponding return-weighted AUC statistic, denoted AUC*. Intuitively, if $\mathrm{AUC}^{*}$ exceeds 0.5 this is evidence that the classifier outperforms the coin toss null from a return-weighted or gain-loss perspective. Detailed derivation of these statistics and their properties are provided in Jordà and Taylor (2009), along with techniques for inference.

Using these return-weighted statistics strongly reinforces our argument that classifiers based on our more refined models (VECM/TECM) are informative; in contrast the performance of the more naïve models are not statistically distinguishable from the coin-toss null. Table 10 collects summary $\mathrm{AUC}^{*}$ statistics for the same in- and out-of-sample periods discussed in Table 9.

The AUC* statistics are higher than the corresponding AUC statistics reported in Table 9, and the $z$-scores attained are much higher too. The VECM and TECM appear to perform better than the other less refined models, with TECM ahead in sample, and VECM slightly ahead out of sample, although the confidence intervals for the AUC measures are overlapping in these cases so there is not much to distinguish them.

Clearly, both of these models are unambiguously better than the coin toss, with a p-value of 0.0001 or less in all cases. This is perhaps to be expected: as we have shown earlier, the major benefit of the models presented here is not the better overall fit, but enhanced ability to get on the right side of big moves - and the weighted $\mathrm{ROC}^{*}$ measure is ideally suited to provide evidence for this advantage. For completeness, Figure 2 shows the ROC* curve for New Zealand that complements the ROC curve in Figure 1. There are no substantive differences - the curves have a similar, slight asymmetric pattern, although in this case as well the AUC* attains a higher value than the AUC in Figure 1. 
Figure 2: A ROC* Curve Example: New Zealand Dollar

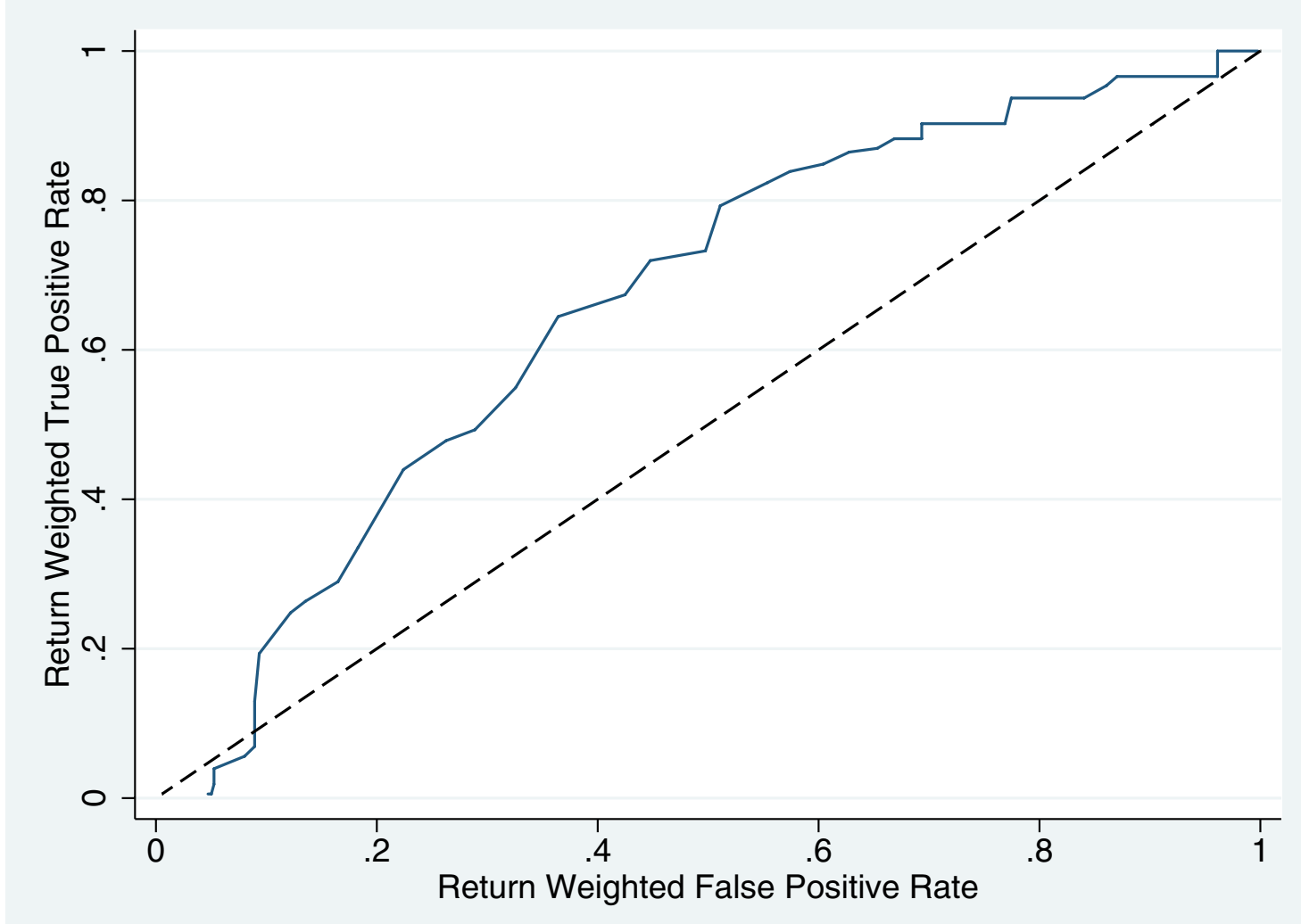

Notes: In-sample predictions using TECM Model. Sample: Apr. 1986 to Dec. 2008. Area under the curve for this case: $\mathrm{AUC}^{*}=0.6631$ (s.e. $=0.0347, \mathrm{z}=4.6941, \mathrm{p}=0.0000$ )

\subsection{Beyond RMSE: Trading-Based Predictive Ability Tests}

The ROC-based tests suggest that our preferred directional models are informative, at least in terms of getting the sign correct more often than a coin toss. But this is not the only performance metric of interest. Do any of our models generate meaningful improvement from a trader's perspective? And are some better than others in this regard? In this section we propose some flexible tests of predictive ability for use in this setting.

Extant tests designed to assess the marginal predictive ability of one model against another are based, generally speaking, on a comparison of the forecast loss function from one model to the other. Such is the approach proposed by the popular Diebold and Mariano (1995) and West (1996) frameworks and subsequent literature, with the usual choice of loss function being the root-mean squared error (RMSE). Yet, as we have noted, overall fit isn't the only, or even the best criterion for evaluating arbitrage possibilities.

The approach that we pursue is to consider a variety of loss functions and use a framework that naturally extends our ROC based analysis. For this purpose we generate a series of out-ofsample, one-period ahead forecasts from a rolling sample of fixed length. It is clear that in this 
type of set-up, estimation uncertainty never vanishes and for this reason we adopt the conditional predictive ability testing methods introduced in Giacomini and White (2006). These tests have the advantage of permitting heterogeneity and dependence in the forecast errors, and their asymptotic distribution is based on the view that the evaluation sample goes to infinity even though the estimation sample remains of fixed length.

Specifically, let $\left\{L_{t+1}^{i}\right\}_{t=R}^{T-1}$ denote the loss function associated with the sequence of one stepahead forecasts, where $R$ denotes the fixed size of the rolling estimation-window from $t=1$ to $T-1$, and let $i=0,1$ (with the index 0 indicating forecasts generated with the unit root null model and the index 1 indicating the alternative model). Then, the test statistic

$$
G W_{1,0}=\frac{\Delta \bar{L}}{\widehat{\sigma}_{L} / \sqrt{P}} \stackrel{d}{\rightarrow} N(0,1)
$$

provides a simple test of predictive ability, where

$$
\Delta \bar{L}=\frac{1}{P} \sum_{t=R}^{T-1}\left(L_{t+1}^{1}-L_{t+1}^{0}\right)
$$

and

$$
\widehat{\sigma}_{L}=\sqrt{\frac{1}{P} \sum_{t=R}^{T-1}\left(L_{t+1}^{1}-L_{t+1}^{0}\right)^{2}}
$$

(since $E(\Delta L)=0$ under the null. See theorem 1 in Giacomini and White, 2006); and where $P=T-R+1$.

The flexibility in defining the loss function permitted in the Giacomini and White (2006) framework is particularly useful for our application. The framework extends naturally to a panel context, where the forecasts for $N$ different currencies over $P$ periods are pooled together. In that case, assuming independence across units in the panel we may implement the above test with the observation count $P$ replaced by $N P$. Because one may suspect that the panel units are not independent, we implement a cluster-robust covariance correction however.

The traditional summary statistic of predictive performance is the well-known root-mean squared error

$$
R M S E_{i}=\sqrt{\frac{1}{P} \sum_{t=R}^{T-1}\left(\widehat{m}_{t+1}^{i}-m_{t+1}\right)^{2}} ; i=0,1
$$

where $\widehat{m}_{t+1}^{i}=E_{t}\left(m_{t+1} \mid\right.$ Model $\left.=i\right)$ for $i=0,1$. Thus, one can assess whether differences in RMSE between models are statistically significant by choosing

$$
L_{t+1}^{i}=\left(\widehat{m}_{t+1}^{i}-m_{t+1}\right)^{2} ; i=0,1
$$

But even if $R M S E$ is a major focus of the academic literature, it is of little interest to those in financial markets, since models with good (poor) fit measured by RMSE could still generate poor (respectively, good) returns (Jordà and Taylor 2009). So what about investors' preferred 
Table 11: Forecast Evaluation: Loss-Function Statistics for Pooled Data

\begin{tabular}{lcccc}
\hline \hline & $\begin{array}{c}\text { RMSE } \\
(\times 100)\end{array}$ & $\begin{array}{c}\text { RTN } \\
\text { (annual \%) }\end{array}$ & $\begin{array}{c}\text { SR } \\
\text { (annual) }\end{array}$ & $\begin{array}{c}\text { SK } \\
\text { (monthly) }\end{array}$ \\
\hline (a) In sample, 1987-2008 & & & & -0.77 \\
Naïve & 2.93 & 3.23 & 1.08 & 0.06 \\
NECM & 2.91 & 4.16 & 1.32 & -0.26 \\
VAR & 2.89 & 5.42 & 1.83 & 0.24 \\
VECM & 2.87 & 6.46 & 2.19 & 0.34 \\
TECM & 2.83 & 7.35 & 2.42 & -1.00 \\
(b) Out of sample, 2004-2008 & & & -1.01 & -0.36 \\
Naïve & 2.23 & -2.84 & -0.21 & $-0.17^{*}$ \\
NECM & $2.22^{*}$ & -0.80 & 0.72 & $0.44^{*}$ \\
VAR & 2.21 & $2.23^{*}$ & 1.22 & $0.64^{*}$ \\
VECM & 2.20 & $3.70^{*}$ & 0.92 & \\
TECM & 2.20 & $3.27^{*}$ & & \\
\hline
\end{tabular}

Notes: * indicates the GW statistic against the Naïve null based on the corresponding loss function, is significant at the $95 \%$ confidence level. To correct for cross-sectional dependence, a cluster-robust covariance correction is used. See text.

performance criteria? Fortunately, the flexibility of the framework allows one to consider loss functions based on alternative metrics. Three natural ways to assess the advantages of different models from the perspective of the trades they generate are as follows:

First, the average return, defined for the evaluation sample as

$$
R T N_{i}=\frac{1}{P} \sum_{t=R}^{T-1} \widehat{\mu}_{t+1}^{i} ; i=0,1 .
$$

Second, the Sharpe ratio, defined for the evaluation sample as

$$
S R_{i}=\frac{\frac{1}{P} \sum_{t=R}^{T-1} \widehat{\mu}_{t+1}^{i}}{\sqrt{\frac{1}{P} \sum_{t=R}^{T-1}\left(\widehat{\mu}_{t+1}^{i}-\bar{\mu}^{i}\right)^{2}}} ; i=0,1
$$

Third, and finally, the skewness of realized returns

$$
S K_{i}=\frac{\sqrt{P(P-1)}}{P-2} \frac{\frac{1}{P} \sum_{t=R}^{T-1}\left(\widehat{\mu}_{t+1}^{i}-\bar{\mu}^{i}\right)^{3}}{\left(\frac{1}{P} \sum_{t=R}^{T-1}\left(\widehat{\mu}_{t+1}^{i}-\bar{\mu}^{i}\right)^{2}\right)^{3 / 2}} ; i=0,1 .
$$

where $\bar{\mu}^{i}=\frac{1}{P} \sum_{t=R}^{T-1} \widehat{\mu}_{t+1}^{i}$ for $i=0,1$. Thus, this Sharpe ratio measures the out-of-sample risk/return profile of the carry trade strategies implied by competing forecasting models, whereas the skewness coefficient allows us to assess the models' ability to avoid infrequent but particularly large negative returns. The associated loss functions are derived as in the case of the RMSE and summarized in the appendix for completeness.

Table 11 summarizes the full in-sample and the out-of-sample loss functions: RMSE (in percent); Annualized Return (in percent); Annualized Sharpe Ratio; and the monthly Skewness 
coefficient for each of the models in Tables 2, 3, and 5; that is the Naïve (null); the Naïve ECM; the VAR, the VECM; and the TECM models. For panel (b), which contains the out-of-sample results, an asterisk indicates that the Giacomini-White (2006) statistic associated to the loss function in that column is significant at the conventional 95\% confidence level (as compared to the Naïve model in row 1). Results for pooled month-year observations are shown. The results in column 1 show that the difference in the models as judged by RMSE are miniscule. However, measured by metrics that matter to traders, the differences are considerable. For example, in our preferred model, in-sample the difference in annual mean returns is +3.23 for Naïve versus +7.35 percent for TECM. Out-of-sample the period includes the period of carry trade crashes, and the difference is -2.84 versus +3.45 percent (panel b). Annual Sharpe Ratios for pooled returns are boosted from +1.08 to +2.42 in-sample, and from -1.01 to +0.92 in the turbulent out-of-sample period. Skewness improves from -0.77 to +0.34 in-sample, and from -1.0 to +0.64 out-of-sample. There is little doubt which of these returns a currency hedge fund manager would have preferred. The GW tests also show that, with the exception of skewness, these performance improvements are statistically significant, out-of-sample, relative to the Naïve model.

\section{Alternative Crash Protection Strategies}

In this section we compare the merits of our fundamentals-based model with the recent literature, where two alternative crash protection strategies have emerged. The first is a contract-based strategy: Burnside, Eichenbaum, Kleshchelski, and Rebelo (2008ab) explore a crash-free trading strategy where FX options are used to hedge against a tail event that takes the form of a collapse in the value of the high-yield currency. The second is a signal based strategy: Brunnermeier et al. (2008) argue that an important cause of carry trade crashes is the arrival of a state of the world characterized by an increase in market volatility or illiquidity.

\subsection{Options}

In Burnside, Eichenbaum, Kleshchelski, and Rebelo (2008ab) a naïve carry trade strategy is the starting point. Traders go long the high yield currencies and short the low yield currencies. The focus is also on major currencies, as here, although the sample window goes back to the 1970s era of capital controls, and applies to a larger set of 20 currencies. Returns may be computed for individual currencies, portfolios, of for subsets of currencies (e.g., groups of 1, 2 or 3 highest yield currencies against similar groups of lowest yield currencies). However, each naïve strategy can be augmented by purchase of at-the-money put options on the long currencies. ${ }^{27}$

This augmentation leads to positive skew by construction. It averts tail risk, but at a price. How large is that price? For the 1987/1 to 2008/1 period a naïve unhedged equally-weighted carry trade had a return of $3.22 \%$ per annum with an annualized Sharpe ratio of 0.54 and a skewness of -0.67. This compares with the U.S. stock market's $6.59 \%$ return, 0.45 Sharpe ratio, and skewness of -1.16 over the same period. Normality of returns is rejected in both cases.

\footnotetext{
27 This strategy is also studied by Bhansali (2007).
} 
Implementing the options-based hedged carry trade boosts the Sharpe ratio a little, eliminates the negative skew, but at a significant cost. Added insurance costs of $0.71 \%$ per annum mean that the hedged strategy lowers returns to only $2.51 \%$ annually, has a Sharpe of 0.71 , and a significant positive skew of 0.75 . Thus on an annualized basis the hedged strategy costs $80 \mathrm{bps}$, and still fails to bring the Sharpe close to the mythical 1.0 hurdle.

In contrast, let us now compare our similar equal-weight naïve carry trading strategy with our nonlinear fundamentals-based return-forecast strategy, in Table 6, panel (a). Comparing Models (1) and (5), our strategy increases returns from 29 to 46 bps per month, and still eliminates negative skew. For comparison, on an annualized basis, the return rises from $3.45 \%$ to $5.55 \%$, a gain of $210 \mathrm{bps}$, with a Sharpe ratio of 1.34. Unlike the options-based strategy, our approach can increase returns and lower skew at the same time.

We make some further observations. To be fair, we recognize that the strategies implemented by Burnside, Eichenbaum, Kleshchelski, and Rebelo (2008ab) are crude and mainly illustrative. The options they employ are at-the-money, and push skew into strong positive territory. In reality, investors might purchase option that are more out-of-the-money; at much lower costs, this could protect against only the large crashes, yet still eliminate the worst of the negative skew (Jurek 2008). Nonetheless, even if lower cost option strategies are found, our results suggest that there is a better no-cost way to hedge against crashes by using data on deviations from long-run fundamentals, and this information also serves to boost absolute returns and Sharpe ratios too. Moreover, options contracts have other drawbacks, many of which were shown to be salient issues after the financial crash of 2008. Option prices embed volatility, so in periods of turmoil the price of insurance can rise just when it is most needed, depending on the implied FX volatility (Bhansali 2007). And as with all derivatives, options carry counterparty risk. In addition, options price and position data from exchanges may not be representative, since this activity represents only a tiny fraction of FX option trading, the vast majority being over-the-counter. Also, like forwards and futures derivatives, options carry bid-ask spreads that can explode such as to make markets dysfunctional in crisis periods. Finally, whilst Burnside, Eichenbaum, Kleshchelski, and Rebelo (2008ab) show the viability of an options-based strategy for 20 widely-traded major currencies, FX derivative markets are thin to nonexistent for many emerging market currencies, and bidask spreads can be wide, so in those markets currency strategists may have to seek alternative plain-vanilla approaches, like ours, that might help avert currency crash risk.

\subsection{VIX Signal}

In Brunnermeier et al. (2008) it is argued that various forms of generalized asset market distress, by reducing risk appetite, may be significant contributors to carry trade crashes. ${ }^{28}$ The logic of the argument is that such conditions may prompt a pull back from all risky asset classes, leading to short-run losses via order flow effects, or the price impact of trades. To provide empirical support for this proposition the authors show that, on a weekly basis, changes in the VIX volatility index (a proxy for distress) correlate with the returns to naïve carry trade strategies - that is, trading

\footnotetext{
${ }^{28}$ Melvin and M.P. Taylor (2009) also examine financial stress as a predictor of carry trade profits.
} 
strategies which do not condition on any information except the interest differential. An increase in VIX was found to correlate with lower carry trade returns, all else equal, suggesting that liquidity risk might partially explain the excess returns. However, lagged changes in VIX had little or no predictive power for next periods returns. This prompts us to explore whether the same arguments hold true in our sample, and if we detect any difference when we use our preferred trading strategy. We found that in our data, using the same 1992-2006 sample period, at a monthly frequency, there was no evidence that the change in VIX was correlated with returns contemporaneously, nor that it helped predict next period's returns.

Specifically, in the spirit of Brunnermeier et al. (2008), we compute "loadings" by regressing our returns on the contemporaneous and lagged change in VIX. We first regressed the actual (signed) returns of trades based on the naïve model on the contemporaneous change in VIX for all months and all currencies in our data over their sample period 1992-2006. We then did the same for the lagged change in VIX. We then re-ran both regressions using the actual (signed) returns of our preferred TECM model. In none of the four regressions was the slope coefficient significant, and in all cases it actually had the "wrong" positive sign, suggesting that rising VIX was slightly positively correlated with profits this month, or next month.

We make some further observations. To be fair, we should note that Brunnermeier et al. (2008) present these results at a weekly frequency. In our dataset, we have to work at monthly frequency given the underlying price index data used to construct the real exchange rate fundamental signal. We conjecture that the VIX signal may have stronger correlations with current or future returns at weekly or even fortnightly frequency, even when placed in a model like ours augmented to account for real exchange rate fundamentals, although further research is warranted in this area.

If the sample is extended using our full dataset, including through the volatile crisis period in 2007-2008, the coefficients are not stable and we do sometimes find a statistically significant role for VIX signals in predicting negative actual (signed) returns of the naïve Model 1, although this episode is outside the window considered by Brunnermeier et al. (2008). But this result disappears, and the sign even reverses, when we include the real exchange rate term and use our preferred TECM model, suggesting that the real exchange rate deviation alone may serve as an adequate crash warning. In fact, in these models the sign of the coefficient on the change in VIX was often positive and significant, suggesting potentially the opposite interpretation: when VIX is rising, arbitrage capital may be being withdrawn, but this has a tendency to leave more profits on the table for the risk tolerant, or "patient capital," and for traders pursuing profitable fundamental-based strategies with inherent skew protection of the sort developed here.

\section{Reality Check: Exchange Traded Funds}

Do our models relate in any way to actual market outcomes? Beyond out-of-sample forecasting, an alternative way to judge our preferred modeling and trading strategies against the naïve benchmark is to compare the recent performances of different currency funds in the real world. When comparing the merits of naïve versus fundamentals-based strategies, the relative performance of these funds in the financial crisis 2008 proves to be very revealing. 
First, we seek a fund representative of the naïve long-short approach, the basic carry strategies of Burnside, Eichenbaum, and Rebelo (2008), and the same authors with Kleshchelski (2008ab), henceforth BER/K. For this purpose we focus on the Deutsche Bank G10 Currency Harvest USD Index (AMEX: DBCFHX, Bloomberg: DBHVG10U). This index has been constructed back to March 1993 using historical data. Since April 2006 this index has been made available to retail investors - in the United States, for example, it trades as the Powershares DB G10 Currency Harvest Fund (AMEX: DBV). These indices track a portfolio based on 2:1 leveraged currency positions selected from ten major "G10" currencies with the U.S. dollar as a base. ${ }^{29}$

This ETF's naïve approach to forecasting any currency pair via the carry signal matches the $\mathrm{BER} / \mathrm{K}$ approach. The main differences are that the index is not equal weight and tries to pick 6 winners out of 9 , the fund's leverage is finite and so this fund has to pay the opportunity costs of satisfying the margin requirement, and the fund also charges a $0.75 \%$ per annum management fee. The performance of the index in the period 2003 to 2008 is shown in Figure 3, where the starting value of the index is rebased to 100. The first four years, up to mid/late 2007 were a golden age for naïve strategies: the index return was about $10 \%$ per year, and the index peaked over 140 in mid-2007. Even after some reversals, as late as the middle of 2008 the index stood at 130, and was up 30\% on January 2003 levels.

Based on a similar, strong performance by their trading strategy through mid-2007, the virtues of a naïve carry trade strategy, protected only by cross-currency diversification, were praised by Burnside, Eichenbaum, and Rebelo $(2008,588)$ :

It is much less obvious what particular peso problem can explain the high Sharpe ratio associated with the equally weighted carry trade. That strategy seems to involve "picking up pennies in front of an unknown truck that has never been seen."

Unfortunately, in the second half of 2008 the Naïve-BER/K type of carry trade strategies were hit by the financial equivalent of a runaway eighteen-wheeler. The index gave up about $10 \%$ in the third quarter and a further $20 \%$ in October in a major unwind. After all that the index stood below its January 2003 level of 100, and four and a half years of gains had been erased.

Could a more sophisticated carry trade strategy have avoided this carnage, whilst still preserving positive returns overall? Yes. To see this we now look for a different index which matches better with our more sophisticated trading strategy. We focus on the Deutsche Bank Currency Returns USD Index (Bloomberg: DBCRUSI). This investible index operates on the same set of "G10" currencies but amalgamates three different trading signals for each currency, where again the signals are +1 (long), 0 (no position), and -1 (short). The first signal is the same as before: the naïve carry trade signal based purely on the interest rate, the 3-month LIBOR rate (The "Carry Index"), updated every three months. The second signal is based a calculation of the deviation of that currency from its FEER level, based on continuously updated common-currency price levels

\footnotetext{
29 Technically, as explained in the DBV prospectus, for every $\$ 1$ invested, the index goes long ( $\$ 1$ total) in the three currencies with the highest interest rates, and short (\$-1 total) in the three with the lowest interest rates, and with 0 invested in the other three, with $\$ 1$ placed in Treasuries as margin. The portfolio is reweighted only every quarter and is implemented via futures contracts. If the U.S. dollar is one of the long or short currencies, that position makes no profit in the base currency and is dropped, so leverage falls to 1.66.
} 
Figure 3: Naïve Carry ETF versus Augmented Carry ETF, 2003-08

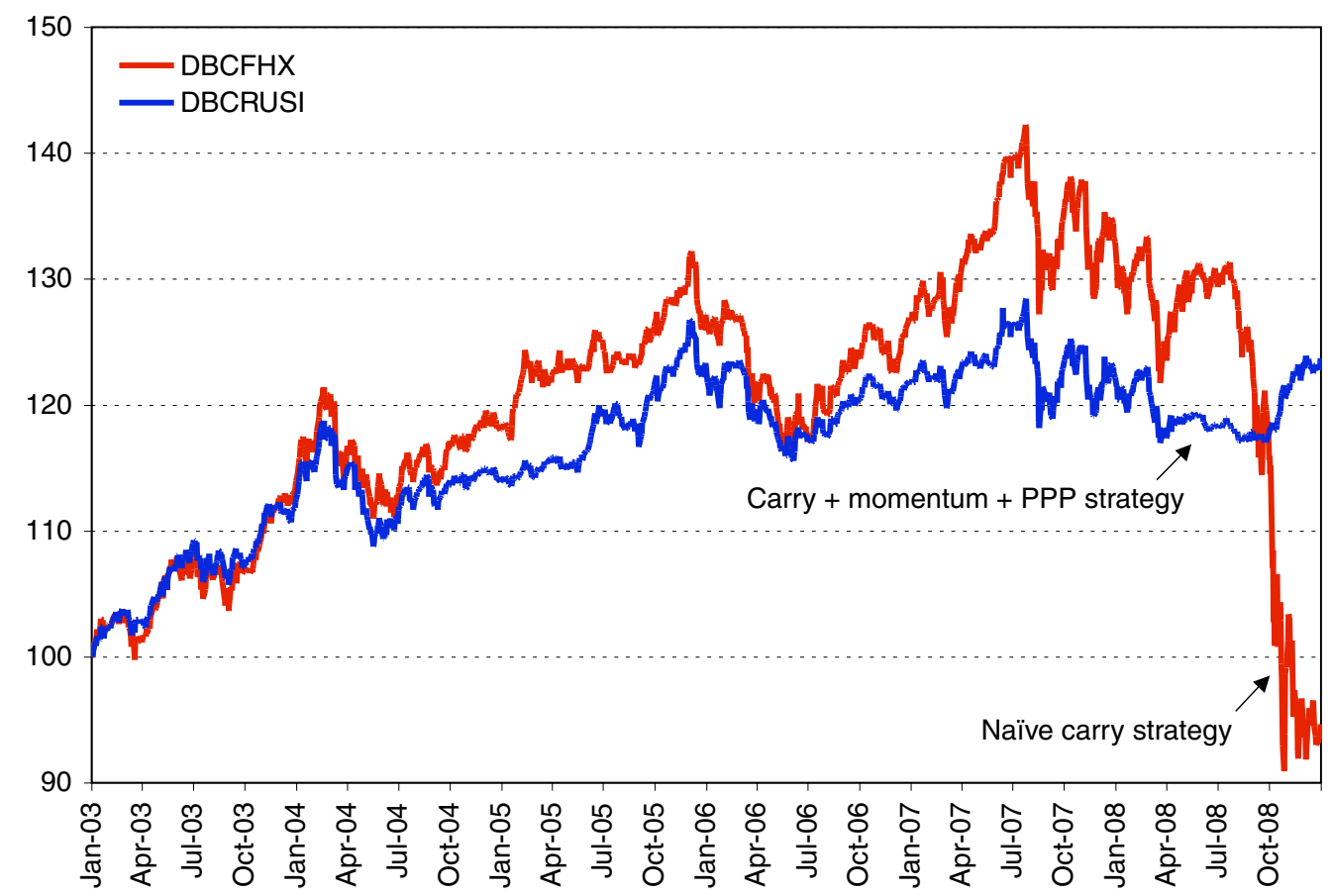

Notes: The ETFs are based the Deutsche Bank G10 Currency Harvest USD Index (DBCFHX) and Deutsche Bank Currency Returns USD Index (DBCRUSI). The indices predate the ETF inception dates.

from the OECD (The "Valuation Index") updated every three months. The third signal is based on momentum, and takes into account the USD return to holding that currency in the previous period (The "Momentum Index") updated every month. Clearly this augmented carry strategy is much closer in spirit to our augmented models, given its mix of signals. In our model "carry" corresponds to the lagged interest differential; "momentum" corresponds mostly to the lagged exchange rate change (given persistence in the interest differential); and "valuation" corresponds to our monthly real exchange rate deviation.

The Deutsche Bank Currency Returns index is not currently available as an exchange traded fund in the U.S., but it is traded as an ETF in Frankfurt. A test of our approach is to ask: did investors in this more sophisticated fund fare better in 2008 than those invested in the naïve DBV fund. As Figure 3 shows, they did much better. On the 2003-07 upswing this index was less volatile, but returns were still strong, up about $28 \%$ at the peak. Momentum signals got the money quickly out of crashing currencies (and back in when they rose), and valuation signals hedged against dangerously overvalued currencies (and jumped in otherwise), tempering the naïve carry signal. The real test was in 2008. The index did remarkably well: performance was absolutely flat returns, and kept $20 \%$ of the cumulative gains locked in. Looking at the three components of this strategy, a $30 \%+$ loss on the carry signal in 2008 , was offset by a $10 \%$ gain on the PPP signal 
and a $20 \%$ gain on the momentum signal.

Notice how the relative performance of these ETFs closely matches the results of our trading strategies as shown back in Table 7. In the out of sample results the Naïve-BER/K type model showed a loss of 2.84\% per year from 2004 to 2008. Our more sophisticated VECM showed a gain of $4.15 \%$ per year. That differential of $7 \%$ per year would cumulate to a roughly $30 \%$ divergence in index values over a four year period. Despite some differences in methods between our model simulations and the ETFs, this is almost exactly the cumulative divergence seen for the real-world ETFs in Figure 3.

Fundamentals matter. Comparing the two ETFs makes clear the gains from using a more sophisticated currency strategy incorporating a FEER measure. Although academic research has focused on the naïve strategies, it is no secret in the financial markets that more refined models, taking into account the signals discussed here and many others, are actively employed by serious fund managers and are now leaking out into traded products. ${ }^{30}$

\section{Conclusion}

The international financial crisis of the second half of 2008 effectively undid the majority of the persistent carry trade returns observed during the previous five to ten years. Strategies based on arbitraging interest rate differentials across countries under the belief that it was equiprobable for exchange rates to appreciate or depreciate displayed consistently positive average returns. But these returns were volatile and subject to occasional crashes (negative skewness). It could be argued then, that the observation of persistent carry trade returns does not violate the efficient markets hypothesis.

This paper instead shows that more sophisticated strategies that incorporate information about the fundamental equilibrium exchange rate can deliver positive returns with high Sharpe ratios and zero or even mildly positive skewness. We do not claim to be better at forecasting exchange rates than the ubiquitous random walk model according to the yardstick in Meese and Rogoff (1983). We claim that we can predict better than the toss of a coin the direction of the carry trade that will produce positive returns. Our results indicate that this is no in-sample fluke and in fact, a thorough out-of-sample analysis that includes the turbulent period of the second-half of 2008, reaffirms the robustness of our claims. Moreover, the historical performance of real-world ETFs during this period (discussed in the previous section) corroborates our findings.

In addition to these findings, our paper makes two contributions to the empirical assessment of the directional predictive potential of alternative investment strategies. On the one hand, we adapt formal predictive ability tests with loss functions that better represent those characteristics that are most important to an investor, which do not necessarily correspond with those that have been traditionally important to an econometrician. Moreover, we introduce in this paper new techniques commonly used in biostatistics, the ROC curve and associated statistics, that are of considerable utility for investors. In a companion paper we have extended the discussion of the techniques introduced here in several dimensions. For instance, among some of the topics we cover,

${ }^{30}$ For example, in addition to the Deutsche Bank ETs, see also the FX Currents from Goldman Sachs. 
we discuss how to evaluate more sophisticated trading strategies that allow for long-short-cash positions (Jordà and Taylor 2009).

We believe that there is more work to be done that builds on the foundations of this paper. In this paper we have considered simple portfolio strategies based on equal weights, but clearly strategies that exploit the time-varying correlation structure across countries beg for more sophisticated portfolio designs. Similarly, a lesson from the ROC analysis introduced in this paper is that directional prediction can be fine-tuned to reflect the marginal trade-offs between return, volatility, and skew encapsulated in each investor's preferences.

More broadly, we view this paper as having introduced carry trade strategies that are still simple - but not naïve - with risk and return characteristics that challenge conventional views about the rewards to risk in currency markets. It is natural to expect that when others test the $\mathrm{EMH}$ in these markets, they will have to address the findings that we have uncovered here.

\section{Appendix}

The loss functions of the Giacomini-White (2006) statistic in expression (4) corresponding to each of the three trading-based metrics, and each model $i=0,1$, are, for returns:

$$
L_{t+1}^{i}=\widehat{\mu}_{t+1}^{i} ; i=0,1
$$

for the Sharpe ratio

$$
L_{t+1}^{i}=\frac{\widehat{\mu}_{t+1}^{i}}{\sqrt{\frac{1}{P} \sum_{t=R}^{T-1}\left(\widehat{\mu}_{t+1}^{i}-\bar{\mu}^{i}\right)^{2}}} ; i=0,1 ;
$$

and for skewness, we use Pearson's second definition of skewness to provide a comparable scale with the returns- and Sharpe ratio-based loss functions, specifically

$$
L_{t+1}^{i}=\frac{3\left(\widehat{\mu}_{t+1}^{i}-\mu^{i}(0.50)\right)}{\sqrt{\frac{1}{P} \sum_{t=R}^{T-1}\left(\widehat{\mu}_{t+1}^{i}-\bar{\mu}^{i}\right)^{2}}} ; i=0,1
$$

where $\mu^{i}(0.50)$ refers to the median of $\widehat{\mu}_{t+1}^{i}$ for $t=R, \ldots, T-1$. The cluster correction that we use for the panel consists in computing the covariance matrix of the loss function difference across countries and standardizing by the inverse of its Cholesky decomposition.

\section{References}

Alexius, Annika. 2001. Uncovered Interest Parity Revisited. Review of International Economics 9(3): 505-17.

Bakker, Age, and Bryan Chapple. 2002. Advanced Country Experiences with Capital Account Liberalization. Occasional Paper 214, Washington, D.C.: International Monetary Fund.

Bacchetta, Philip, and Eric van Wincoop. 2006. Can Information Heterogeneity Explain the Exchange Rate Determination Puzzle? American Economic Review 96(3): 552-76.

Bekaert, Geert, and Robert J. Hodrick. 1993. On Biases in the Measurement of Foreign Exchange Risk Premiums. Journal of International Money and Finance 12(2): 115-38. 
Bernardo, Antonio E., and Ledoit, Olivier. 2000. Gain, Loss and Asset Pricing. Journal of Political Economy 108(1): 144-72.

Bhansali, Vineer. 2007. Volatility and the Carry Trade, Journal of Fixed Income 17(3): 72-84.

Bilson, John F. O. 1981. The "Speculative Efficiency" Hypothesis. Journal of Business 54(3): 435-51.

Bilson, John F. O. 1984. Purchasing Power Parity as a Trading Strategy. Journal of Finance. 39(3): 715-24.

Brunnermeier, Markus K., Stefan Nagel, and Lasse H. Pedersen. 2008. Carry Trades and Currency Crashes. NBER Working Papers 14473.

Burnside, A. Craig. 2007. The Cross-Section of Foreign Currency Risk Premia and Consumption Growth Risk: A Comment. NBER Working Papers 13129.

Burnside, A. Craig, Martin Eichenbaum, Isaac Kleshchelski, and Sergio Rebelo. 2006. The Returns to Currency Speculation. NBER Working Papers 12489.

Burnside, A. Craig, Martin Eichenbaum, Isaac Kleshchelski, and Sergio Rebelo. 2008a. Do Peso Problems Explain the Returns to the Carry Trade? CEPR Discussion Papers 6873, June.

Burnside, A. Craig, Martin Eichenbaum, Isaac Kleshchelski, and Sergio Rebelo. 2008b. Do Peso Problems Explain the Returns to the Carry Trade? NBER Working Papers 14054.

Burnside, A. Craig, Martin Eichenbaum, and Sergio Rebelo. 2007. The Returns to Currency Speculation in Emerging Markets. NBER Working Papers 12916.

Burnside, A. Craig, Martin Eichenbaum and Sergio Rebelo. 2008. Carry Trade: The Gains of Diversification. Journal of the European Economic Association 6(2-3): 581-88.

Cheung, Yin-Wong, Menzie D. Chinn, and Antonio Garcia Pascual. 2005. Empirical Exchange Rate Models of the Nineties: Are Any Fit to Survive? Journal of International Money and Finance 24(7): 1150-75.

Chinn, Menzie D., and Jeffrey A. Frankel. 2002. Survey Data on Exchange Rate Expectations: More Currencies, More Horizons, More Tests. In Monetary Policy, Capital Flows and Financial Market Developments in the Era of Financial Globalisation: Essays in Honour of Max Fry, edited by W. Allen and D. Dickinson. London: Routledge, 145-67.

Clarida, Richard, and Daniel Waldman. 2007. Is Bad News About Inflation Good News for the Exchange Rate? NBER Working Papers 13010.

Clinton, Kevin. 1998. Transactions Costs and Covered Interest Arbitrage: Theory and Evidence. Journal of Political Economy 96: 358-70.

Coakley, Jerry, and Ana María Fuertes. 2001. A Non-linear Analysis of Excess Foreign Exchange Returns. Manchester School 69(6): 623-42.

Conover, W. J. 1999. Practical Nonparametric Statistics. 3rd edition. New York: John Wiley and Sons.

DeMiguel, Victor, Lorenzo Garlappi, and Raman Uppal. 2009. Optimal Versus Naive Diversification: How Inefficient is the 1/N Portfolio Strategy? Review of Financial Studies 22(5): 1915-53.

Diebold, Francis X., and Roberto S. Mariano. 1995. Comparing Predictive Accuracy. Journal of Business and Economic Statistics 13(3): 253-63.

Dominguez, Kathryn M. 1986. Are Foreign Exchange Forecasts Rational? New Evidence from Survey Data. Economics Letters 21(3): 277-81.

Dooley, Michael P., and Jeffrey R. Shafer. 1984. Analysis of Short-Run Exchange Rate Behavior: March 1973 to 1981. In Floating Exchange Rates and The State of World Trade and Payments, edited by David Bigman and Teizo Taya, 43-70. 
Engel, C., and James D. Hamilton. 1990. Long Swings in the Dollar: Are They in the Data and Do Markets Know It? American Economic Review 80(4): 689-711.

Fackler, Martin. 2007. Japanese Housewivwes Sweat in Secret as Markets Reel. New York Times, September 16, 2007.

Fama, Eugene F. 1984. Forward and Spot Exchange Rates. Journal of Monetary Economics 14(3): $319-38$.

Fawcett, Tom. 2006. ROC Graphs with Instance-Varying Costs. Pattern Recognition Letters 27(8): $882-91$.

Fisher, Eric O'N. 2006. The Forward Premium in a Model with Heterogeneous Prior Beliefs. Journal of International Money and Finance 25(1): 48-70.

Flood, Robert P., and Mark P. Taylor. 1996. Exchange Rate Economics: What's Wrong with the Conventional Macro Approach? In The Microstructure of Foreign Exchange Markets, edited by Jeffrey A. Frankel, Giampaolo Galli, and Alberto Giovannini. Chicago: University of Chicago Press, pp. 261302

Frankel, Jeffrey A. 1980. Tests of Rational Expectations in the Forward Exchange Market. Southern Economic Journal 46(4): 1083-1101.

Frankel, Jeffrey A., and Kenneth A. Froot. 1987. Using Survey Data to Test Standard Propositions Regarding Exchange Rate Expectations. American Economic Review 77(1): 133-53.

Frenkel, Jacob A., and Richard M. Levich. 1975. Covered Interest Rate Arbitrage: Unexploited Profits? Journal of Political Economy 83(2): 325-38.

Froot, Kenneth A., and Jeffrey A. Frankel. 1989. Forward Discount Bias: Is It an Exchange Risk Premium? The Quarterly Journal of Economics 104(1): 139-61.

Froot, Kenneth A., and Tarun Ramadorai. 2008. Institutional Portfolio Flows and International Investments. Review of Financial Studies 21(2): 937-71.

Froot, Kenneth A., and Richard H. Thaler. 1990. Foreign Exchange. Journal of Economic Perspectives $4(3): 179-92$.

Fujii, Eiji, and Menzie D. Chinn. 2000. Fin de Siècle Real Interest Parity. NBER Working Papers 7880.

Giacomini, Raffaella, and Halbert White. 2006. Tests of Conditional Predictive Ability. Econometrica 74(6): 1545-78.

Granger, Clive W. J., and Timo Teräsvirta. 1993. Modelling Nonlinear Economic Relationships. Oxford: Oxford University Press.

Hand, David J., and Veronica Vinciotti. 2003. Local versus Global Models for Classification Problems: Fitting Models Where It Matters. The American Statistician 57: 124-31.

Hansen, Lars Peter, and Robert J. Hodrick. 1980. Forward Exchange Rates as Optimal Predictors of Future Spot Rates: An Econometric Analysis. Journal of Political Economy 88(5): 829-53.

Ilut, Cosmin. 2008. Ambiguity Aversion: Implications for the Uncovered Interest Rate Parity Puzzle. Northwestern University. Photocopy.

Jeanne, Olivier, and Andrew K. Rose. 2002. Noise Trading And Exchange Rate Regimes. Quarterly Journal of Economics 117(2): 537-69.

Jordà, Òscar, and Alan M. Taylor. 2009. Investment Performance of Directional Trading Strategies. University of California, Davis. Photocopy.

Jurek, Jakub W. 2008. Crash-Neutral Currency Carry Trades. Princeton University. Photocopy.

Levich, Richard M., and Lee R. Thomas, III. 1993. The Significance of Technical Trading-Rule Profits in the Foreign Exchange Market: A Bootstrap Approach. Journal of International Money and Finance 
12(5): 451-74.

Lusted, Lee B. 1960. Logical Analysis in Roentgen Diagnosis. Radiology 74: 178-93.

Lustig, Hanno, and Adrien Verdelhan. 2007. The Cross Section of Foreign Currency Risk Premia and Consumption Growth Risk. American Economic Review 97(1): 89-117.

Lyons, Richard K. 2001. The Microstructure Approach to Exchange Rates. Cambridge, Mass.: MIT Press.

Mason, Ian B. 1982. A Model for the Assessment of Weather Forecasts. Australian Meterological Society 30: 291-303.

Meese, Richard A., and Kenneth Rogoff. 1983. Empirical Exchange Rate Models of the Seventies. Journal of International Economics 14(1-2): 3-24.

Melvin, Michael, and Mark P. Taylor. 2009. The Crisis in the Foreign Exchange Market. CEPR Discussion Paper 7472, September. Forthcoming in the Journal of International Money and Finance.

Michael, Panos, A. Robert Nobay, and David A. Peel. 1997. Transactions Costs and Nonlinear Adjustment in Real Exchange Rates: An Empirical Investigation. Journal of Political Economy 105(4): 862-79.

Obstfeld, Maurice, and Alan M. Taylor. 1997. Nonlinear Aspects of Goods-Market Arbitrage and Adjustment: Heckscher's Commodity Points Revisited. Journal of the Japanese and International Economies 11(4): 441-79.

Obstfeld, Maurice, and Alan M. Taylor. 2004. Global Capital Markets: Integration, Crisis, and Growth. Cambridge: Cambridge University Press.

Pedroni, Peter. 1999. Critical Values for Cointegration Tests in Heterogeneous Panels with Multiple Regressors. Oxford Bulletin of Economics and Statistics 61: 653-70.

Pedroni, Peter. 2004. Panel Cointegration: Asymptotic and Finite Sample Properties of Pooled Time Series Tests with an Application to the PPP Hypothesis. Econometric Theory 20(3): 597-625.

Pepe, Margaret S. 2003. The Statistical Evaluation of Medical Tests for Classification and Prediction. Oxford: Oxford University Press.

Pesaran, M. Hashem, Yongcheol Shin, and Ronald P. Smith. 1999. Pooled Mean Grouped Estimation of Dynamic Heterogeneous Panels. Journal of the American Statistical Association 94: 621-24.

Peterson, W. Wesley, and Theodore G. Birdsall. 1953. The Theory of Signal Detectability: Part I. The General Theory. Electronic Defense Group, Technical Report 13, June 1953. Available from EECS Systems Office, University of Michigan.

Plantin, Guillaume, and Hyun Song Shin. 2007. Carry Trades and Speculative Dynamics. Princeton University. Photocopy.

Pojarliev, Momtchil, and Richard M. Levich. 2007. Do Professional Currency Managers Beat the Benchmark? NBER Working Papers 13714.

Pojarliev, Momtchil, and Richard M. Levich. 2008. Trades of the Living Dead: Style Differences, Style Persistence and Performance of Currency Fund Managers. NBER Working Papers 14355.

Poterba, James M., and Lawrence H. Summers. 1986. The Persistence of Volatility and Stock Market Fluctuations. American Economic Review 76(5): 1142-51.

Pritchard, Ambrose Evans. 2007. Goldman Sachs Warns of Dead Bodies After Market Turmoil. The Daily Telegraph, June 3, 2007.

Sager, Michael, and Mark P. Taylor. 2008. Generating Currency Trading Rules from the Term Structure of Forward Foreign Exchange Premia. University of Warwick, October. Photocopy.

Sarno, Lucio, and Mark P. Taylor. 2002. The Economics of Exchange Rates. Cambridge: Cambridge University Press. 
Sarno, Lucio, Giorgio Valente, and Hyginus Leon. 2006. Nonlinearity in Deviations from Uncovered Interest Parity: An Explanation of the Forward Bias Puzzle. Review of Finance 10(3): 443-82.

Shleifer, Andrei, and Robert W. Vishny. 1997. A Survey of Corporate Governance. Journal of Finance 52(2): $737-83$.

Silvennoinen, Annastiina, Timo Teräsvirta, and Changli He. 2008. Unconditional Skewness from Asymmetry in the Conditional Mean and Variance. Department of Economic Statistics, Stockholm School of Economics. Photocopy.

Sinclair, Peter J. N. 2005. How Policy Rates Affect Output, Prices, and Labour, Open Economy Issues, and Inflation and Disinflation. In How Monetary Policy Works, edited by Lavan Mahadeva and Peter Sinclair. London: Routledge.

Spackman, Kent A. 1989. Signal Detection Theory: Valuable Tools for Evaluating Inductive Learning. In Proceedings of the Sixth International Workshop on Machine Learning. Morgan Kaufman, San Mateo, Calif., 160-63.

Swets, John A. 1973. The Relative Operating Characterstic in Psychology. Science 182: 990-1000.

Taylor, Alan M., and Mark P. Taylor. 2004. The Purchasing Power Parity Debate. Journal of Economic Perspectives 18(4): 135-58.

Taylor, Mark P., David A. Peel, and Lucio Sarno. 2001. Nonlinear Mean-Reversion in Real Exchange Rates: Toward a Solution to the Purchasing Power Parity Puzzles. International Economic Review 42(4): 1015-42.

West, Kenneth D. 1996. Asymptotic Inference about Predictive Ability. Econometrica 64(5): 1067-84. 